\title{
Synthesis, Antiplasmodial and Antitrypanosomal Evaluation of a Series of Novel 2-Oxoquinoline-based Thiosemicarbazone Derivatives
}

\author{
Oliver T. Darrell ${ }^{a}$, Siyabonga T. Hulushe ${ }^{a}$, Thanduxolo E. Mtshare ${ }^{a} \mathbb{D}^{\S}$, \\ Richard M. Beteck ${ }^{a}$, Michelle Isaacs ${ }^{b}$, Dustin Laming ${ }^{b}$, Heinrich C. Hoppe ${ }^{b, c}$, \\ Rui W.M. Krause ${ }^{a, b}$ and Setshaba D. Khanye $e^{a, b, d, *(D)}$ \\ ${ }^{a}$ Department of Chemistry, Rhodes University, Grahamstown, 6140, South Africa. \\ ${ }^{b}$ Centre for Chemico- and Biomedicinal Research, Rhodes University, Grahamstown, 6140, South Africa. \\ ${ }^{c}$ Department of Biochemistry and Microbiology, Rhodes University, Grahamstown, 6140, South Africa. \\ ${ }^{d}$ Faculty of Pharmacy, Rhodes University, Grahamstown, 6140, South Africa.
}

Received 26 March 2018, revised 7 November 2018, accepted 10 November 2018

\begin{abstract}
Herein a series of novel thiosemicarbazones (TSCs) derived from 2-oxoquinoline scaffold is reported, and the target compounds have been successfully synthesized and characterized using standard spectroscopic techniques. The in vitro biological activities of synthesized molecules were evaluated against Plasmodium falciparum malaria parasites (strain 3D7), Trypanosoma brucei brucei parasites (strain 427) and HeLa cells. All the compounds displayed modest or no activity at a concentration of $20 \mu \mathrm{M}$ and percentage viability of $>50 \%$ was often observed. Except for compound 9o, none of the final compounds exhibited cytotoxic effects against HeLa cells at $20 \mu \mathrm{M}$.
\end{abstract}

KEYWORDS

Trypanosoma brucei, trypanosomiasis, Plasmodium falciparum, thiosemicarbazones, 2-oxoquinoline.

\section{Introduction}

Malaria, an infectious parasitic disease, is a major health risk in many developing countries worldwide. ${ }^{1}$ Despite tremendous progress over the last two decades, in 2017 there were 216 million cases of malaria infection, with an estimated 445000 deaths, $90 \%$ of which occur in sub-Saharan Africa. ${ }^{1,2}$ Currently, it is estimated that almost 3.2 billion people globally are at risk of contracting the disease. ${ }^{3}$ This is further aggravated by the widespread drug and multidrug resistant Plasmodium falciparum parasite, the main cause of infection in humans, to almost all antimalarial drugs that are in clinical use. ${ }^{4}$ In the absence of an effective malaria vaccine, the need to discover and develop new antimalarial drugs, with unique structural motifs and new mode of action, that are safe and effective against highly resistant parasites is imperative. ${ }^{4,5}$

On other hand, human African trypanosomiasis (HAT), commonly referred to as a sleeping sickness, is caused by protozoan parasites of the genus Trypanosoma, and the two species that are transmitted to humans by blood-feeding tsetse flies (Glossina spp.) are Trypanosoma brucei gambiense and Trypanosoma brucei rhodesiense. ${ }^{6,7} \mathrm{Up}$ to 70 million people, in various parts of the 36 countries in Africa where the disease is endemic, are at risk of infection. ${ }^{6}$ While the cases of HAT in Africa have been reasonably low, in 2015 an estimated 3000 new infections of East and West African trypanosomiasis were reported to the World Health Organisation (WHO). ${ }^{8}$ Regrettably, in pregnant women or those of child-bearing age, the disease causes infertility and abortion, and it is invariably fatal if left untreated. ${ }^{8}$ Currently, only a handful of drugs are available for the treatment of HAT,

* To whom correspondence should be addressed. E-mail: s.khanye @ ru.ac.za and are utilized based on the causative trypanosome species and stage of the disease. ${ }^{8}$ For example, pentamidine and suramin are recommended for treatment of the acute initial stage of T. $b$. gambiense, while a combination of nifurtimox-eflornithine and melarsoprol are deployed for the secondary stage of the disease. For T. b. rhodesiense, suramin is a preferred drug for treatment of the initial stage of the disease, while melarsoprol is reserved for secondary stage chemotherapy. ${ }^{9}$ However; these drugs have shortcomings and some of them are associated with lifethreatening side effects that have prompted the scientific community to search for new compounds with desirable safety margins and drug-like properties to replace them.

Thiosemicarbazones are a class of compounds which have enjoyed significant attention due to their broad-spectrum of biological activities, including antibacterial, antiprotozoal, antifungal, antiviral and antitumour activity. ${ }^{10}$ Quinoline and related derivatives, on the other hand, are useful compounds with diverse pharmaceutical applications, and some have even reached markets for treatment of various ailments. ${ }^{11}$ The 2-oxoquinoline (2-OCQ), which belongs to a quinoline family, is an interesting naturally occurring scaffold to attach new moieties or bioactive groups and it has been widely used as a 'parental' framework to synthesize a variety of molecules with a wide range of biological activities such as antitubercular, antiinflammatory, antifungal and antileishmanial activity. ${ }^{12-15}$ For example, oxoquinoline-derived thiosemicarbazones I and III (Fig. 1) were found to exhibit good antiproliferative activity against the HCT116 cell line. ${ }^{16}$

In our pursuit of developing biologically relevant molecules, that could address some of the problems associated with 
<smiles>NC(=S)N/N=c1\[nH]c2ccccc2c(O)c1[N+](=O)[O-]</smiles>

।<smiles>NC(=S)N/N=C/c1cc2ccccc2[nH]c1=O</smiles>

II

Figure 1 Chemical structures of biologically active quinoline-derived thiosemicarbazone derivatives (I and II) based on 2-oxo-quinoline structural motif.

infections caused by protozoan parasites, we are interested in exploring a class of 2-oxoquinoline-derived thiosemicarbazone derivatives as antiplasmodial and antitrypanosomal agents. To the best of our knowledge, there has been no report on the antiplasmodial and antitrypanosomal properties of these compounds in literature. To this end, in this study we report on the synthesis of quinoline-derived thiosemicarbazones and their in vitro bioassay screening against $P$. falciparum $3 \mathrm{D} 7$ strain and
T. b. brucei (strain 427) as well as cytotoxicity evaluation against HeLa cell lines.

\section{Results and Discussion}

\subsection{Synthesis}

The synthesis of target quinoline-derived thiosemicarbazone derivatives is outlined in Scheme 1. Commercially available<smiles>Nc1ccccc1</smiles><smiles>[R]c1ccc(NC(C)=O)cc1</smiles><smiles>[R]c1ccc2nc(Cl)c(C=O)cc2c1</smiles>

$$
\begin{aligned}
& \text { 1a: } R=H \\
& \text { 1b: } R=4-\mathrm{OCH}_{3} \\
& \text { 1c: } \mathrm{R}=4-\mathrm{CH}_{3}
\end{aligned}
$$

2a: $\mathbf{R}=\mathbf{H}$ 2b: $\mathbf{R}=\mathrm{OCH}_{3}$ 2c: $\mathbf{R}=\mathrm{CH}_{3}$

$$
\begin{aligned}
& \text { 3a: } \mathrm{R}=\mathrm{H} \\
& \text { 3b: } \mathrm{R}=\mathrm{OCH}_{3} \\
& \text { 3c: } \mathrm{R}=\mathrm{CH}_{3}
\end{aligned}
$$
iii<smiles>[CH][TeH]</smiles>

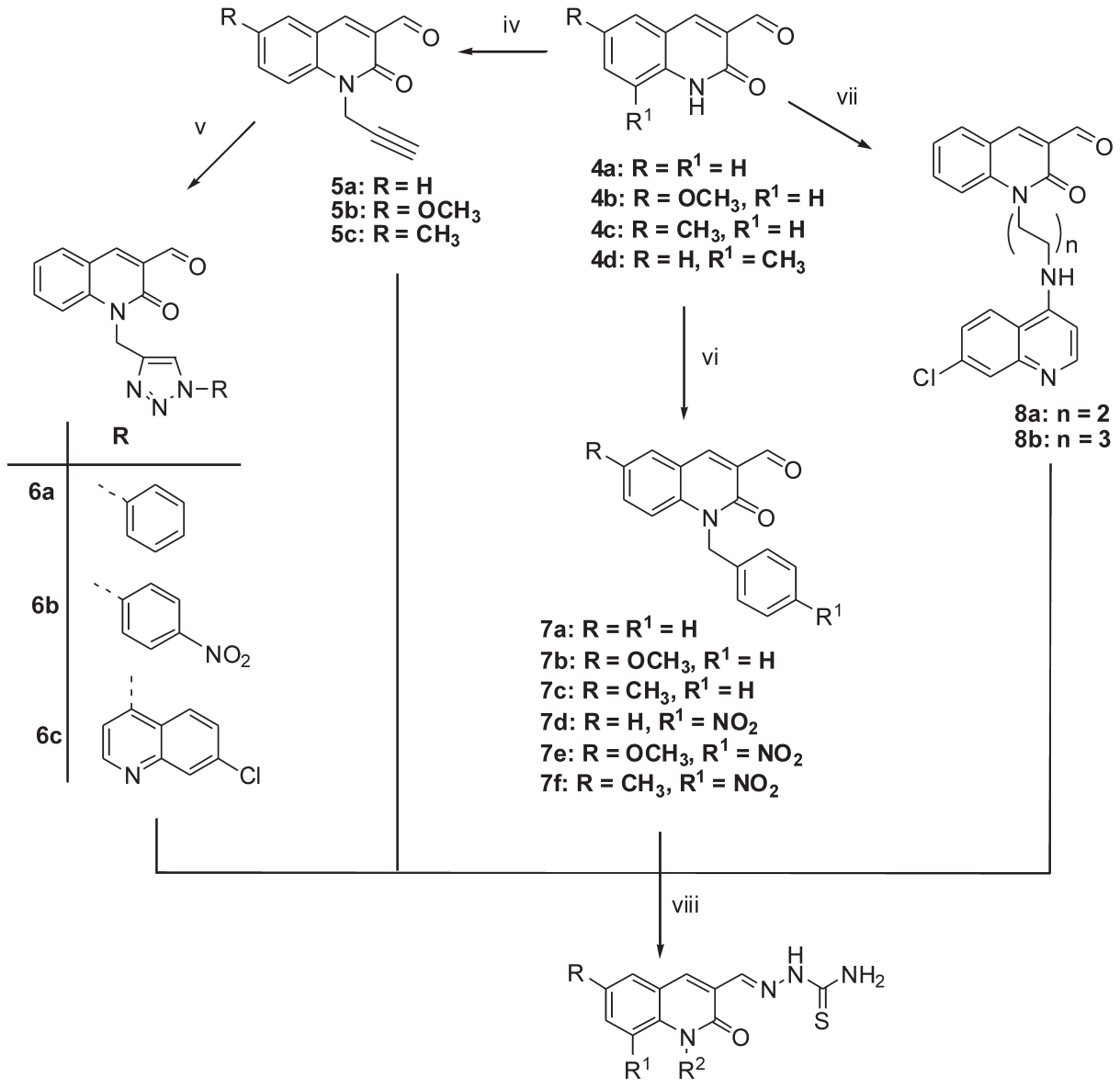

$9 a-r$

Scheme 1

(i) Acetic acid, acetic anhydride (1:1), reflux, $0.5 \mathrm{~h}$; (ii) $\mathrm{DMF}, \mathrm{POCl}_{3}, 85^{\circ} \mathrm{C}, 12 \mathrm{~h}$; (iii) acetic acid, $90^{\circ} \mathrm{C}, 8 \mathrm{~h}$; (iv) propargyl bromide, $\mathrm{DMF}_{2} \mathrm{~K}_{2} \mathrm{CO}_{3}$, $25-60{ }^{\circ} \mathrm{C}, 4 \mathrm{~h}$; (v) azide, CuI, 2,6-lutidine, $0{ }^{\circ} \mathrm{C}, 12 \mathrm{~h}$; (vi) benzylbromides $\left(\mathrm{R}^{3}-\mathrm{X}\right.$ ), DMF, $\mathrm{K}_{2} \mathrm{CO}_{3}, \mathrm{r} . \mathrm{t}-60^{\circ} \mathrm{C}, 1-12 \mathrm{~h}$; (vii) aminoquinolines, $\mathrm{DMF}, 0{ }^{\circ} \mathrm{C}$, $\mathrm{NaH}, 1 \mathrm{~h}, 60^{\circ} \mathrm{C}, 12 \mathrm{~h}$; (viii) thiosemicarbazide, $\mathrm{MeOH}$ or EtOH, $80^{\circ} \mathrm{C}, 10-15 \mathrm{~h}$. 
anilines 1a-c were treated with a solution of acetic acid and acetic anhydride (1:1 mole ratio) under reflux to generate the corresponding acetanilides $\mathbf{2 a - c}$ in moderate yields. ${ }^{17}$ The Vilsmeier-Haack reaction ${ }^{18}$ involving the condensation of resultant acetanilides 2a-c with $N, N$-dimethylformamide (DMF), in the presence of phosphorusoxychloride $\left(\mathrm{POCl}_{3}\right)$, was then used to produce 2-chloroquinoline-3-carbaldehyde derivatives $\mathbf{3 a - c .}{ }^{18}$

The next step involved accessing the desired key intermediates, 2-oxoquinoline-3-carbaldehyde derivatives $4 \mathbf{a}-\mathbf{d}$, via a previously reported literature methods. ${ }^{19}$ Thus, the hydrolytic reaction of $3 \mathbf{a}-\mathbf{c}$ in $70 \%$ acetic acid aqueous solution resulted in quinolinone derivatives $\mathbf{4 a - c}$, which were obtained in yields ranging from $38-62 \%$. To access compounds $4 \mathrm{~d}$, commercial available 2-chloroquinoline-3-carbaldehyde was reacted, under similar reaction conditions as in the synthesis of $4 \mathbf{a}-\mathbf{c}$, to yield the desired compound $4 \mathbf{d}$ in $69 \%$ yield. With the desired key intermediates $(\mathbf{4 a - c})$ in hand, propargylation reaction using propargyl bromide yielded propargyl quinoline aldehydes $\mathbf{5 a - c}$, which were then further reacted with appropriate azides, under the copper-catalyzed azide-alkyne cycloaddition (CuAAC) conditions ${ }^{20-23}$ to form 1,4-disubstituted-1,2,3-triazoles quinoline aldehydes $6 \mathbf{a}-\mathrm{c}$ in yields ranging from $42-61 \%$.

Similarly, reacting the key intermediates $4 \mathbf{a}-\mathbf{c}$ with substituted benzylbromides and 7-chloro- $N$-(2-chloropropyl)quinolin4 -amine yielded quinoline aldehydes $\mathbf{7 a - f}$ and $\mathbf{8 b}$ in moderate yields, respectively. Compound $\mathbf{8 a}$ could not be isolated in its pure form, and instead it was reacted with thiosemicarbazide (step viii) as crude product to form the desired quinolinederived thiosemicarbazone $9 \mathrm{n}$. Lastly, all the quinoline aldehydes $\mathbf{5 a}-\mathbf{c}, \mathbf{6 a}-\mathbf{c}, \mathbf{7 a - f}$ and $\mathbf{8 b}$ were then subjected to the Schiff base condensation reaction with commercially accessible thiosemicarbazide in refluxing $\mathrm{MeOH}$ or $\mathrm{EtOH}$ to give rise to the desired 2-oxoquinoline-based thiosemicarbazone derivatives 9a-r (Table 1) in moderate to excellent yields. ${ }^{24-26}$ All the intermediates and target compounds were fully characterized by analytical and spectroscopic techniques.

\subsection{In Vitro Biological Evaluation}

The prepared target compounds were evaluated in vitro for antiplasmodial activity against the chloroquine sensitive (CQS) 3D7 P. falciparum, the trypanosomal subspecies responsible for nagana T. $b$. brucei, and for cytotoxicity evaluation using a human cervix adenocarcinoma (HeLa) cell line. Chloroquine (CQ) was included as a positive control for $P$. falciparum and pentamidine (PMD) was employed for T. b. brucei assays while emetine (EMT) was a positive control drug for HeLa cells. The screening assay was done using the malaria parasite lactate dehydrogenase $P f(\mathrm{pLDH})$, T. $b$. brucei and HeLa cell resazurin assays that were performed in duplicates using $20 \mathrm{mM}$ final concentrations of each compound. The percentage cell viability results upon exposure of P. falciparum, T. b. brucei and HeLa cells to the compounds are displayed in Table 2.

The tested compounds (Table 2) exhibited no cytotoxic effects (percentage viability $>64 \%$ ) as measured by the viability of HeLa cell lines at a concentration of $20 \mu \mathrm{M}$, the exception is compound 9o which reduced HeLa cell viability to $6.6 \%$. Excluding compounds $9 \mathrm{~m}, 9 \mathrm{n}$ and $9 \mathrm{o}$, which reduced the percentage parasite viability to below $20 \%$, none of the tested target compounds displayed desirable potency at the concentration of $20 \mu \mathrm{M}$. These compounds were evaluated further to determine the corresponding $\mathrm{IC}_{50}$ values (Fig. 2) against the 3D7 strain of the parasite $P$. falciparum. And while $9 \mathrm{~m}$ emerged as inactive, compounds $9 \mathrm{n}$ and $9 \mathrm{o}$ displayed notable activity with the corresponding $\mathrm{IC}_{50}$ values of 2.09 and $1.79 \mu \mathrm{M}$, respectively. These
Table 1 Synthesized quinoline-based thiosemicarbazones 9a-r and their isolated yields.<smiles>NC(=S)N/N=C/c1cc2cc(Br)ccc2[nH]c1=O</smiles>

Comp

data suggest that the observed antiplasmodial activity may be related to the presence of aminoquinoline moiety in each molecule, which is known to bind with haem, thus preventing the formation of haemozoin. However, the corresponding quinoline aldehyde intermediates $6 c$ and $8 b$ were ineffective (data not included) at the maximum tested concentration 
Table 2: In vitro antiplasmodial and antitrypanosomal activity, and cytotoxicity evaluation of target compounds $9 \mathbf{a}-\mathbf{r}$. The $\mathrm{IC}_{50}$ values (in $\mu \mathrm{M}$ ) obtained with the standard drug compounds CQ, PMD and EMT are also shown.

\begin{tabular}{lccc}
\hline & \multicolumn{3}{c}{ \% Viability at $20 \mu \mathrm{M}$} \\
\cline { 2 - 4 } Comp & $3 \mathrm{D} 7$ & T. brucei & Cytotoxicity \\
\hline 9a & 79.1 & 114.5 & 84.8 \\
9b & 66.1 & 103.1 & 64.8 \\
9c & 78.5 & 115.1 & 110.2 \\
9d & 81.6 & 112.3 & 95.1 \\
9e & 97.1 & 116.1 & 89.9 \\
9f & 49.3 & 104.3 & 85.1 \\
9g & 97.1 & 52.8 & 102.3 \\
9h & 81.6 & 118.4 & 83.3 \\
9i & 72.2 & 108.6 & 96.0 \\
9j & 101.4 & 102.3 & 94.1 \\
9k & 103.9 & 92.7 & 62.0 \\
91 & 85.9 & 111.7 & 111.2 \\
9m & $\mathbf{1 7 . 6}$ & 90.3 & 100.2 \\
9n & $\mathbf{- 2 . 5}$ & $\mathbf{1 2 . 7}$ & 90.8 \\
9o & $-\mathbf{4 . 4}$ & $\mathbf{1 2 . 8}$ & $\mathbf{6 . 6}$ \\
9p & 87.0 & 115.3 & 112.4 \\
9q & $\mathbf{7 4 . 5}$ & 98.8 & 106.8 \\
9r & 31.3 & 112.8 & 105.5 \\
CQ & $\mathbf{0 . 0 2 8}$ & - & - \\
PMD & - & $\mathbf{0 . 0 0 2 8}$ & - \\
EMT & - & - & $\mathbf{0 . 3 7}$ \\
\hline
\end{tabular}

( $20 \mathrm{mM}$ ) suggesting that enhanced activity of $9 \mathbf{n}$ and 90 could be attributed to the contribution of the thiosemicarbazone and 4-aminoquinoline fragments. ${ }^{27}$

Similarly, in terms of antitrypanosomal activity, none of the tested compounds exhibited appreciable activity except compounds $9 \mathbf{n}$ and 90 , which reduced the viability of trypanosomes (T. b. brucei) at $20 \mu \mathrm{M}$ to $12.7 \%$ and $12.8 \%$, respectively. Since compound 9o showed a significant cytotoxic effect at $20 \mu \mathrm{M}$, only compound $9 \mathrm{n}$ was further screened to determine the corresponding $\mathrm{IC}_{50}$ value (Fig. 3). Despite significant growth inhibition as measured by the viability of trypanosomes, compound 9n was found to be inactive with $\mathrm{IC}_{50}$ value of $167.7 \mu \mathrm{M}$.

\section{Conclusion}

In summary, a series of thiosemicarbazone derivatives $9 a-r$ based on the 2-oxoquinoline structural motif have been prepared in moderate to excellent yields and their structural integrity confirmed using various spectroscopic techniques. Despite the poor antiplasmodial and antitrypanosomal activity of the majority of the tested compounds, the promising potency of $9 \mathrm{n}$ and $9 \mathrm{o}$ provides an avenue for further in-depth investigation of these bi-quinoline thiosemicarbazone compounds as a new family of quinoline-based anti-infective agents. Apart from compounds 9m, 9n and 9o, which exhibited weak to good activity with $\mathrm{IC}_{50}$ (T. b. brucei) $=167.7 \mu \mathrm{M}$ and $\mathrm{IC}_{50} \mathrm{~s}(\mathrm{Pf})=2.09$ and $1.79 \mu \mathrm{M}$ values, the rest of compounds were inactive and parasite percentage viabilities of $>50 \%$ were often observed. As determined by the HeLa cell line, the majority of these compounds showed no significant toxicity.

\section{Experimental}

\subsection{General}

All commercially available chemicals and reagents were purchased from Sigma-Aldrich (Pty) Ltd and Merck (Pty) Ltd, and were used without further purification unless stated otherwise. The progress of reactions were monitored by analytical thin layer chromatography (TLC) using Merck $\mathrm{F}_{254}$ silica gel plates (supported on aluminium), which were visualized under ultraviolet (UV 254 and $366 \mathrm{~nm}$ ) light or, where necessary, stained in iodine flask. The crude compounds were purified by flash column chromatography using Merck Kieselgel 60 A: 70-230 silica gel mesh or by preparative thin-layer chromatography (PTLC) using Merck $60 \mathrm{GF}_{254}$ silica gel coated on glass plates $(2.0 \times 200 \times$ $200 \mathrm{~mm})$. The ${ }^{1} \mathrm{H}$ and ${ }^{13} \mathrm{CNMR}$ spectra were recorded on either a Bruker Fourier 300 or a $400 \mathrm{MHz}$ spectrometer. Spectra were recorded in deuterated solvents: $\mathrm{CDCl}_{3}-d_{6}$ and DMSO- $d_{6}$. All chemical shift values are reported in parts per million (ppm) referenced to residual solvent resonances $\left(\mathrm{CDCl}_{3} \delta_{\mathrm{H}} 7.26, \delta_{\mathrm{C}} 77.2\right.$; DMSO $\left.\delta_{\mathrm{H}} 2.50, \delta_{\mathrm{C}} 39.5\right)$. The coupling constants are given in Hertz. High resolution mass spectrometry was performed on a Waters Synapt G2 TOF instrument with an ESI source, University of Stellenbosch. Measurement of the melting points was carried out using a Reichert hot stage microscope (Protea Holdings Ltd.) and uncorrected. Elemental microanalysis was per-

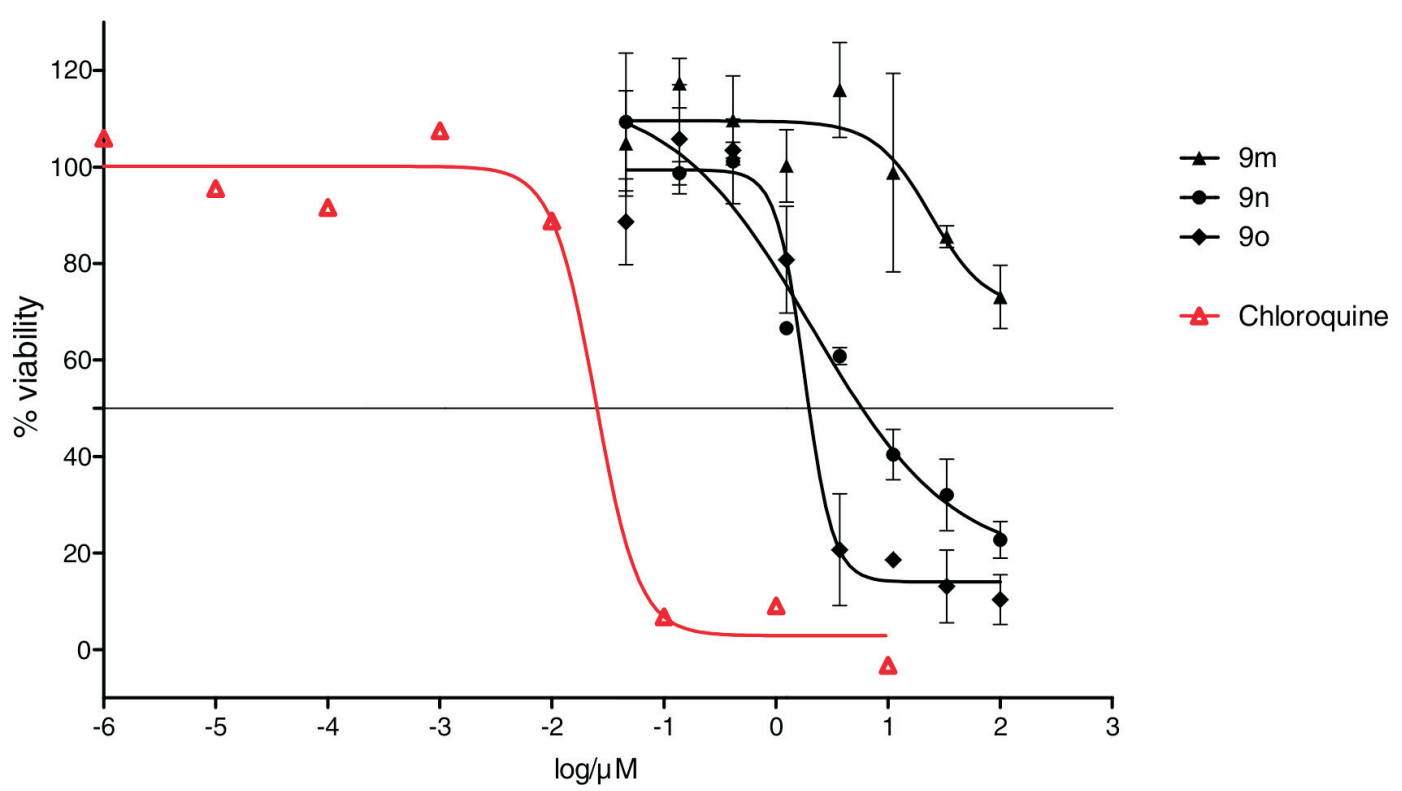

Figure 2 Plot of percentage antiplasmodial activity against log concentration for compounds $9 \mathrm{~m}, 9 \mathrm{n}$, 90 and the standard drug, chloroquine. 


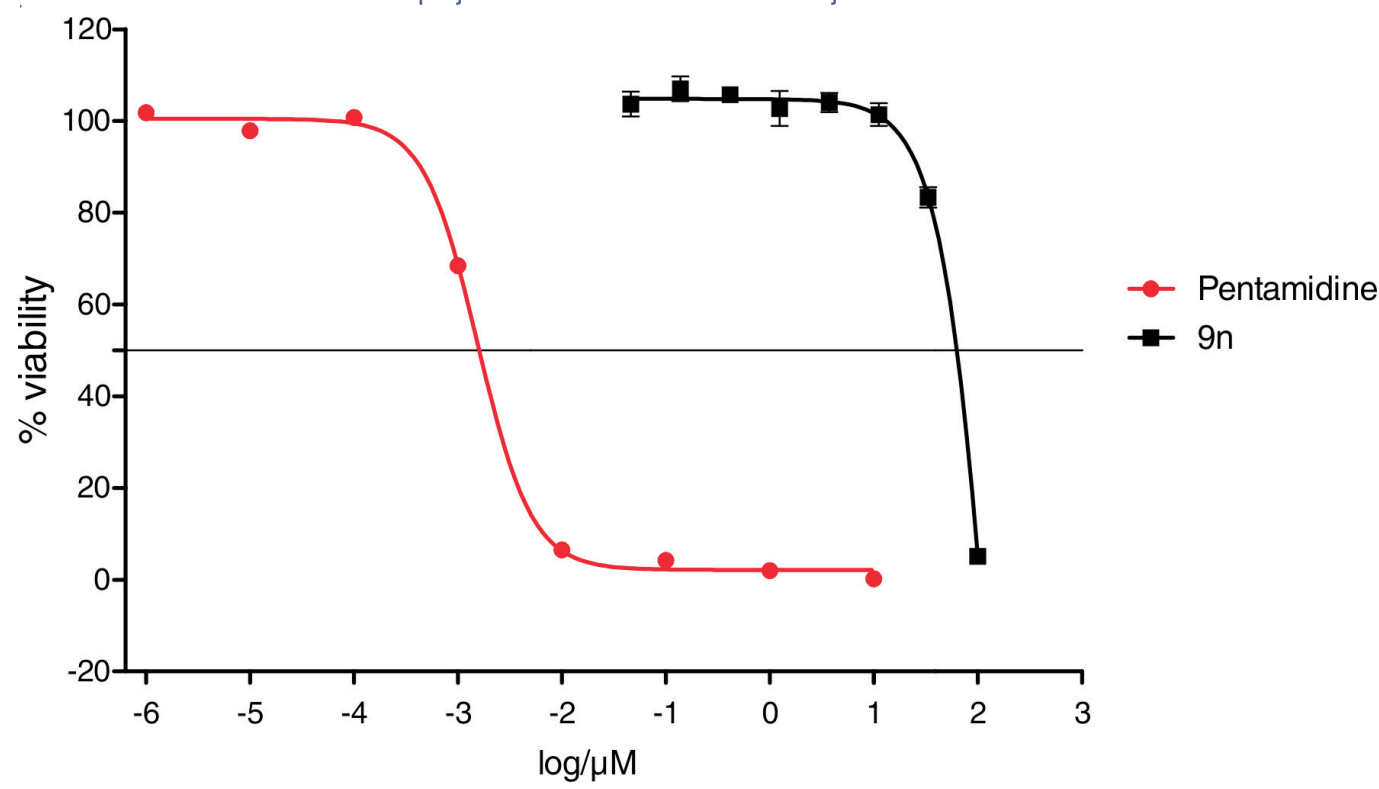

Figure 3 Plot of percentage antitrypanosomal activity against log concentration for compound 9 n and the standard drug, pentamidine.

formed on Elementar Analysensysteme varioMICRO V1.6.2 $\mathrm{GmbH}$ analysis system.

\subsection{General Procedure for Synthesis of Thiosemicarbazone Compounds 9a-r}

An appropriate starting 2-oxoquinoline-3-carbaldehyde $(0.081$ $\mathrm{g}, 0.5)$, and thiosemicarbazide $(0.5 \mathrm{mmol})$ were mixed in methanol $(25 \mathrm{~mL})$ and heated to $80^{\circ} \mathrm{C}$ for $10 \mathrm{~h}$. After reaction completion, the resulting product was allowed to cool to ambient temperature and resulted in the formation of a precipitate, which was filtered, washed with ice-cold $\mathrm{MeOH}$ and dried to give the desired products.

(E)-2-((2-oxo-1,2-dihydroquinolin-3-yl)methylene)hydrazinecarbothioamide (9a): $70 \%$ yield; yellow solid; mp $290-293{ }^{\circ} \mathrm{C}\left(\mathrm{Lit}^{28}\right.$ $\left.296^{\circ} \mathrm{C}\right) ; \delta_{\mathrm{H}}\left(300 \mathrm{MHz} ; \mathrm{DMSO}-\mathrm{d}_{6}\right): 12.1(1 \mathrm{H}, \mathrm{s}, \mathrm{N}(1) \mathrm{H}), 11.7(1 \mathrm{H}, \mathrm{s}$, $\mathrm{N}(11) \mathrm{H}), 8.83\left(1 \mathrm{H}, \mathrm{s}, \mathrm{H}_{4}\right), 8.76\left(1 \mathrm{H}, \mathrm{s}, \mathrm{H}_{9}\right), 8.32(1 \mathrm{H}, \mathrm{br} \mathrm{s}, \mathrm{NHH}), 8.27$ $\left(1 \mathrm{H}, \mathrm{s}, \mathrm{H}_{4}\right), 8.11(1 \mathrm{H}, \mathrm{br} \mathrm{s}, \mathrm{NHH}), 7.64(1 \mathrm{H}, \mathrm{dd}, J=1.1$ and $8.0 \mathrm{~Hz}$, $\left.\mathrm{H}_{5}\right), 7.52\left(1 \mathrm{H}, \mathrm{ddd}, J=1.4,7.3\right.$ and $\left.9.2 \mathrm{~Hz}, \mathrm{H}_{6}\right), 7.30(1 \mathrm{H}, \mathrm{dd}, J=0.8$ and $\left.8.0 \mathrm{~Hz}, \mathrm{H}_{8}\right), 7.22\left(1 \mathrm{H}, \mathrm{ddd}, J=0.9,7.3\right.$ and $\left.9.1 \mathrm{~Hz}, \mathrm{H}_{7}\right) \mathrm{ppm}$; $\delta_{\mathrm{C}}\left(75 \mathrm{MHz}, \mathrm{DMSO}-\mathrm{d}_{6}\right): 178.1,161.0,139.0,136.8,135.2,131.1$, $128.6,125.4,122.5,119.3,115.3$ ppm; $v_{\max }\left(\right.$ neat, $\left.\mathrm{cm}^{-1}\right)$ : $3291(\mathrm{NH})$, $3173(\mathrm{NH}), 1638(\mathrm{C}=\mathrm{O}), 1533(\mathrm{C}=\mathrm{S}), 851(\mathrm{C}-\mathrm{S})$; HRMS (ESI) $\mathrm{m} / \mathrm{z}$ calcd for $\mathrm{C}_{11} \mathrm{H}_{10} \mathrm{~N}_{4} \mathrm{OS} 246.0575$, found $247.0662[\mathrm{M}+\mathrm{H}]^{+}$; Anal. calcd for $\mathrm{C}_{11} \mathrm{H}_{10} \mathrm{~N}_{4} \mathrm{OS} \cdot 0.125 \mathrm{H}_{2} \mathrm{O}: \mathrm{C}, 53.16 ; \mathrm{H}, 4.16 ; \mathrm{N}, 22.54$; S, $12.90 \%$. Found: C, 53.18; H, 3.95; N, 22.54; S, $12.96 \%$.

(E)-2-((8-Methyl-2-oxo-1,2-dihydroquinolin-3-yl)methylene)hydrazinecarbothioamide (9b): $63 \%$ yield; yellow solid; mp 246-248 ${ }^{\circ} \mathrm{C}$; $\delta_{\mathrm{H}}\left(300 \mathrm{MHz} ; \mathrm{DMSO}-\mathrm{d}_{6}\right): 11.6(1 \mathrm{H}, \mathrm{s}, \mathrm{N}(1) \mathrm{H}), 11.2(1 \mathrm{H}, \mathrm{s}, \mathrm{N}(11) \mathrm{H})$ $8.76\left(1 \mathrm{H}, \mathrm{s}, \mathrm{H}_{9}\right), 8.29(2 \mathrm{H}, \mathrm{s}, \mathrm{NHH}), 8.28\left(1 \mathrm{H}, \mathrm{s}, \mathrm{H}_{4}\right), 8.01(1 \mathrm{H}, \mathrm{br} \mathrm{s}$, $\mathrm{NHH}), 7.50\left(1 \mathrm{H}, \mathrm{d}, J=7.8 \mathrm{~Hz}, \mathrm{H}_{5}\right), 7.37\left(1 \mathrm{H}, \mathrm{d}, J=7.5 \mathrm{~Hz}_{7} \mathrm{H}_{7}\right), 7.14$ $\left(1 \mathrm{H}, \mathrm{t}, J=8.0 \mathrm{~Hz}, \mathrm{H}_{6}\right), 2.43\left(3 \mathrm{H}, \mathrm{s}, \mathrm{CH}_{3}\right) \mathrm{ppm} ; \delta_{\mathrm{C}}(75 \mathrm{MHz}$, DMSO-d $)_{6}$ : $\delta_{\mathrm{C}} 178.1,161.5,137.3,136.7,135.8,132.3,126.7,125.0$, 123.6, 122.2, 119.3, 17.2 ppm; $v_{\max }\left(\right.$ neat, $\left.\mathrm{cm}^{-1}\right): 3269(\mathrm{NH}), 3154$ $(\mathrm{NH}), 1645(\mathrm{C}=\mathrm{O}), 1531(\mathrm{C}=\mathrm{S}), 856$ (C-S); HRMS (ESI) $\mathrm{m} / z$ calcd for $\mathrm{C}_{12} \mathrm{H}_{12} \mathrm{~N}_{4} \mathrm{OS}$ : 260.0732, found 261.0808 [M+H] $]^{+}$; Anal. calcd for $\mathrm{C}_{12} \mathrm{H}_{12} \mathrm{~N}_{4} \mathrm{OS} \cdot 0.75 \mathrm{H}_{2} \mathrm{O}$ : C, 52.64; $\mathrm{H}, 4.97 ; \mathrm{N}, 20.46 ; \mathrm{S}, 11.71 \%$. Found: C, 52.61; H, 4.97; N, 20.48; S, $11.57 \%$.

(E)-2-((6-Methyl-2-oxo-1,2-dihydroquinolin-3-yl)methylene)hydrazinecarbothioamide, (9c): $60 \%$ yield; orange solid; $\mathrm{mp} 248-250{ }^{\circ} \mathrm{C}$; $\delta_{\mathrm{H}}\left(300 \mathrm{MHz} ; \mathrm{DMSO}-\mathrm{d}_{6}\right): 11.9(1 \mathrm{H}, \mathrm{s}, \mathrm{N}(1) \mathrm{H}), 11.6(1 \mathrm{H}, \mathrm{s}, \mathrm{N}(11) \mathrm{H})$, $8.68\left(1 \mathrm{H}, \mathrm{s}, \mathrm{H}_{9}\right), 8.29(1 \mathrm{H}, \mathrm{br} \mathrm{s}, \mathrm{NHH}), 8.27\left(1 \mathrm{H}, \mathrm{s}, \mathrm{H}_{4}\right), 8.07(1 \mathrm{H}, \mathrm{s}$, $\mathrm{NHH}), 7.27\left(3 \mathrm{H}, \mathrm{m}, \mathrm{H}_{5}, \mathrm{H}_{7}\right.$ and $\left.\mathrm{H}_{8}\right) 2.33\left(3 \mathrm{H}, \mathrm{s}, \mathrm{CH}_{3}\right)$ ppm; $\delta_{\mathrm{C}}\left(75 \mathrm{MHz}, \mathrm{DMSO}-\mathrm{d}_{6}\right): \delta 178.1,160.9,137.0,136.9,134.7,132.3$, $131.3,127.9,125.2,119.2,115.1,20.4$ ppm; $v_{\max }\left(\right.$ neat, $\left.\mathrm{cm}^{-1}\right): 3256$ $(\mathrm{NH}), 3148(\mathrm{NH}), 1525(\mathrm{C}=\mathrm{N}), 1646(\mathrm{C}=\mathrm{N}), 1208(\mathrm{C}=\mathrm{S}), 863$ (C-S); HRMS (ESI) $\mathrm{m} / \mathrm{z}$ calcd for $\mathrm{C}_{12} \mathrm{H}_{12} \mathrm{~N}_{4} \mathrm{OS}[\mathrm{M}+\mathrm{H}]^{+}$260.0732, found 261.0823; Anal. calcd for $\mathrm{C}_{12} \mathrm{H}_{12} \mathrm{~N}_{4} \mathrm{OS} \cdot 0.75 \mathrm{H}_{2} \mathrm{O}$ : C, 52.64; H, 4.97; N, 20.46; S,11.71 \%. Found: C, 52.51; H, 5.08; N, 20.13; S, $11.50 \%$.

(E)-2-((6-Methoxy-2-oxo-1,2-dihydroquinolin-3-yl)methylene)hydrazinecarbothioamide (9d): $69 \%$ yield; orange solid; mp $255-256{ }^{\circ} \mathrm{C}$ (Lit. $\left.{ }^{29} 258-260{ }^{\circ} \mathrm{C}\right) ; \delta_{\mathrm{H}}\left(300 \mathrm{MHz} ; \mathrm{DMSO}-\mathrm{d}_{6}\right): 11.8(1 \mathrm{H}, \mathrm{s}, \mathrm{N}(1) \mathrm{H})$, $11.6(1 \mathrm{H}, \mathrm{s}, \mathrm{N}(11) \mathrm{H}), 8.72\left(1 \mathrm{H}, \mathrm{s}, \mathrm{H}_{9}\right), 8.31(1 \mathrm{H}$, br s, NHH), 8.27 $\left(1 \mathrm{H}, \mathrm{s}, \mathrm{H}_{4}\right), 8.05(1 \mathrm{H}, \mathrm{br} \mathrm{s}, \mathrm{NHH}), 7.26\left(1 \mathrm{H}, \mathrm{d}, J=8.9 \mathrm{~Hz} \mathrm{H}_{8}\right), 7.18$ $\left(1 \mathrm{H}, \mathrm{dd}, J=2.8\right.$ and $\left.8.9 \mathrm{~Hz}, \mathrm{H}_{7}\right), 7.12\left(1 \mathrm{H}, \mathrm{d}, J=2.8 \mathrm{~Hz}_{3} \mathrm{H}_{5}\right), 3.71$ $\left(3 \mathrm{H}, \mathrm{s}, \mathrm{CH}_{3}\right) \mathrm{ppm} ; \delta_{\mathrm{C}}\left(75 \mathrm{MHz}, \mathrm{DMSO}-\mathrm{d}_{6}\right): 178.1,160.5,154.4$, 136.8, 134.7, 133.6, 125.6, 120.5, 119.7, 116.5, 109.2, 55.4 ppm; $v_{\max }\left(\right.$ neat, $\left.\mathrm{cm}^{-1}\right): 3392(\mathrm{NH}), 3160(\mathrm{NH}), 1647(\mathrm{C}=\mathrm{O}), 1530(\mathrm{C}=\mathrm{S})$, 840 (C-S); HRMS (ESI) $\mathrm{m} / \mathrm{z}$ calcd for $\mathrm{C}_{12} \mathrm{H}_{12} \mathrm{~N}_{4} \mathrm{O}_{2} \mathrm{~S}: 276.0681$, found $277.0747[\mathrm{M}+\mathrm{H}]^{+}$. Anal. Calcd for $\mathrm{C}_{12} \mathrm{H}_{12} \mathrm{~N}_{4} \mathrm{O}_{2} \mathrm{~S}$ : C, 52.16; $\mathrm{H}, 4.38 ; \mathrm{N}, 20.28 ; \mathrm{S}, 11.60$. Found (\%): C, 52.11; H, 4.28; N, 20.23; $\mathrm{S}, 11.57 \%$.

(E)-2-((1-Benzyl-2-oxo-1,2-dihydroquinolin-3-yl)methylene)hydrazinecarbothioamide (9e): $42 \%$ yield; yellow solid; mp 222-224 ${ }^{\circ} \mathrm{C}$; $\delta_{\mathrm{H}}\left(400 \mathrm{MHz} ; \mathrm{DMSO}-\mathrm{d}_{6}\right): 11.7(1 \mathrm{H}, \mathrm{s}, \mathrm{N}(11) \mathrm{H}), 8.86\left(1 \mathrm{H}, \mathrm{s}, \mathrm{H}_{9}\right)$, $8.39\left(1 \mathrm{H}, \mathrm{s}, \mathrm{H}_{4}\right), 8.34(1 \mathrm{H}$, br s, $\mathrm{NHH}), 8.14(1 \mathrm{H}$, br s, $\mathrm{NHH}), 7.73$ $\left(1 \mathrm{H}, \mathrm{dd}, J=1.2\right.$ and $\left.7.8 \mathrm{~Hz}, \mathrm{H}_{5}\right), 7.53(1 \mathrm{H}, \mathrm{ddd}, J=1.4,7.5$ and 8.6 $\left.\mathrm{Hz}, \mathrm{H}_{6}\right), 7.43-7.18(7 \mathrm{H}, \mathrm{m}, \mathrm{Ar}-\mathrm{Hs}), 5.57\left(2 \mathrm{H}, \mathrm{s}, \mathrm{H}_{1 \mathrm{a}}\right) \mathrm{ppm}$; $\delta_{\mathrm{C}}\left(101 \mathrm{MHz}, \mathrm{DMSO}-\mathrm{d}_{6}\right): 178.1,160.6,138.9,137.0,135.7,134.7$, 131.3, 129.6, 128.6, 127.1, 126.5, 124.5, 122.7, 120.2, 115.2, 45.0 ppm; $v_{\max }\left(\right.$ neat, $\left.\mathrm{cm}^{-1}\right): 3201(\mathrm{NH}), 3147(\mathrm{NH}), 1626(\mathrm{C}=\mathrm{O}), 1517(\mathrm{C}=\mathrm{N})$, $1207(\mathrm{C}=\mathrm{S}), 855$ (C-S); HRMS (ESI) $\mathrm{m} / \mathrm{z}$ calcd for $\mathrm{C}_{18} \mathrm{H}_{16} \mathrm{~N}_{4} \mathrm{OS}$ 336.1045, found $337.1136[\mathrm{M}+\mathrm{H}]^{+}$; Anal. calcd for $\mathrm{C}_{18} \mathrm{H}_{16} \mathrm{~N}_{4} \mathrm{OS}$ : C, 64.26; H, 4.79; N, 16.65; S, 9.53. Found: C, 65.16; H, 5.86; $\mathrm{N}, 14.99 ; \mathrm{S}, 8.63 \%$.

(E)-2-((1-(4-Nitrobenzyl)-2-oxo-1,2-dihydroquinolin-3-ylyl)methylene)hydrazinecarbothioamide (9f): $52 \%$ yield; yellow solid; mp 235-237 ${ }^{\circ} \mathrm{C} ; \delta_{\mathrm{H}}\left(400 \mathrm{MHz}\right.$; DMSO-d $\left.\mathrm{d}_{6}\right): 11.7(1 \mathrm{H}, \mathrm{s}, \mathrm{N}(11) \mathrm{H}), 8.89$ $\left(1 \mathrm{H}, \mathrm{s}, \mathrm{H}_{9}\right), 8.38\left(1 \mathrm{H}, \mathrm{s}, \mathrm{H}_{4}\right), 8.36(1 \mathrm{H}, \mathrm{br} \mathrm{s}, \mathrm{NHH}), 8.20-8.16(2 \mathrm{H}, \mathrm{m}$, $\mathrm{H}_{3^{\prime}}$ and $\left.\mathrm{H}_{5^{\prime}}\right), 8.15(1 \mathrm{H}$, br s, $\mathrm{NHH}), 7.76\left(1 \mathrm{H}, \mathrm{d}, J=7.6 \mathrm{~Hz}, \mathrm{H}_{8}\right), 7.54$ 
$\left(1 \mathrm{H}, \mathrm{t}, J=8.7 \mathrm{~Hz}, \mathrm{H}_{6}\right), 7.37\left(1 \mathrm{H}, \mathrm{d}, J=8.7 \mathrm{~Hz}, \mathrm{H}_{5}\right), 7.31(2 \mathrm{H}, \mathrm{t}, 7.4$ $\left.\mathrm{Hz}, \mathrm{H}_{7}\right), 5.70\left(2 \mathrm{H}, \mathrm{s}, \mathrm{H}_{1 \mathrm{a}}\right)$ ppm; $\delta_{\mathrm{C}}\left(101 \mathrm{MHz}, \mathrm{DMSO}-\mathrm{d}_{6}\right): 178.1$, 160.6, 146.6, 144.6, 138.7, 136.8, 135.0, 131.5, 129.8, 127.8, 124.6, 123.8, 123.0, 120.3, 115.3, 44.9 ppm; $v_{\max }\left(\right.$ neat, $\left.\mathrm{cm}^{-1}\right): 3216(\mathrm{NH})$, $3148(\mathrm{NH}), 1633(\mathrm{C}=\mathrm{O}), 1516(\mathrm{C}=\mathrm{N}), 1203(\mathrm{C}=\mathrm{S}), 850(\mathrm{C}-\mathrm{S})$; HRMS (ESI) $\mathrm{m} / z$ calcd for $\mathrm{C}_{18} \mathrm{H}_{13} \mathrm{~N}_{5} \mathrm{O}_{3} \mathrm{~S} 381.0896$, found 382.0968 $[\mathrm{M}+\mathrm{H}]^{+}$; Anal. calcd for $\mathrm{C}_{18} \mathrm{H}_{13} \mathrm{~N}_{5} \mathrm{O}_{3} \mathrm{~S} \cdot 0.5 \mathrm{CH}_{3} \mathrm{OH}: \mathrm{C}$, 56.19; H, 3.82; N, 17.71; S, 8.11 \%. Found: C, 56.61; H, 3.91; N, 17.38; $\mathrm{S}, 8.34 \%$.

(E)-2-((1-Benzyl-6-methoxy-2-oxo-1,2-dihydroquinolin-3-yl)methylene)hydrazinecarbothioamide $(\mathbf{9 g})$ : $41 \%$ yield; yellow solid; $\mathrm{mp}$ 232-234 $\left.{ }^{\circ} \mathrm{C}, \delta_{\mathrm{H}}(400 \mathrm{MHz} \text {; DMSO-d })_{6}\right): \delta 11.7(1 \mathrm{H}, \mathrm{s}, \mathrm{N}(11) \mathrm{H}), 8.81$ $\left(1 \mathrm{H}, \mathrm{s}, \mathrm{H}_{9}\right), 8.38\left(1 \mathrm{H}, \mathrm{s}, \mathrm{H}_{4}\right), 8.36(1 \mathrm{H}$, br s, NHH$), 8.09(1 \mathrm{H}, \mathrm{br} \mathrm{s}$, $\mathrm{NHH}), 7.36-7.27\left(3 \mathrm{H}, \mathrm{m}, \mathrm{H}_{5}, \mathrm{H}_{7}\right.$ and $\left.\mathrm{H}_{8}\right), 7.25-7.15(5 \mathrm{H}, \mathrm{m}$, $\mathrm{H}_{2^{\prime}}, \mathrm{H}_{3^{\prime}}, \mathrm{H}_{4^{\prime}}, \mathrm{H}_{5^{\prime}}$ and $\left.\mathrm{H}_{6^{\prime}}\right), 5.57\left(2 \mathrm{H}, \mathrm{s}, \mathrm{H}_{1 \mathrm{a}}\right), 3.79\left(3 \mathrm{H}, \mathrm{s}, \mathrm{CH}_{3}\right)$ ppm; $\delta_{\mathrm{C}}\left(101 \mathrm{MHz}, \mathrm{DMSO}-\mathrm{d}_{6}\right)$ : 178.1, 160.1, 154.4, 137.1, 136.6, 134.3, $133.5,128.6,127.0,126.5,124.9,120.9,120.0,116.6,110.8,55.4$, 45.0 ppm; $v_{\max }\left(\right.$ neat, $\left.\mathrm{cm}^{-1}\right): 3275(\mathrm{NH}), 3157(\mathrm{NH}), 1635(\mathrm{C}=\mathrm{O})$, $1518(\mathrm{C}=\mathrm{N}), 1202(\mathrm{C}=\mathrm{S}), 869$ (C-S); HRMS (ESI) $\mathrm{m} / \mathrm{z}$ calcd for $\mathrm{C}_{19} \mathrm{H}_{18} \mathrm{~N}_{4} \mathrm{O}_{2} \mathrm{~S}$ : 366.1150 , found $367.1213[\mathrm{M}+\mathrm{H}]^{+}$; Anal. calcd for $\mathrm{C}_{19} \mathrm{H}_{18} \mathrm{~N}_{4} \mathrm{O}_{2} \mathrm{~S} \cdot 0.25 \mathrm{H}_{2} \mathrm{O} ; \mathrm{C}, 61.52 ; \mathrm{H}, 5.03 ; \mathrm{N}, 15.10 ; \mathrm{S}, 8.64 \%$. Found: C, 61.37; H, 4.92; N, 15.03; S, $8.72 \%$.

(E)-2-((6-Methoxy-1-(4-nitrobenzyl)-2-oxo-1,2-dihydroquinolin-3-yl )methylene)hydrazinecarbothioamide (9h): $57 \%$ yield; yellow solid; mp 238-240 ${ }^{\circ} \mathrm{C} ; \delta_{\mathrm{H}}\left(400 \mathrm{MHz} ; \mathrm{DMSO}-\mathrm{d}_{6}\right): 11.7(1 \mathrm{H}, \mathrm{s}, \mathrm{N}(11) \mathrm{H})$, $8.85\left(1 \mathrm{H}, \mathrm{s}, \mathrm{H}_{4}\right), 8.37(1 \mathrm{H}$, br s, NHH), $8.17(2 \mathrm{H}, \mathrm{d}, J=8.8 \mathrm{~Hz}$, $\mathrm{H}_{3^{\prime}}$ and $\left.\mathrm{H}_{5^{\prime}}\right), 8.10(1 \mathrm{H}$, br s, $\mathrm{NHH}), 7.45\left(2 \mathrm{H}, \mathrm{d}, J=8.8 \mathrm{~Hz}, \mathrm{H}_{2^{\prime}}\right.$ and $\left.\mathrm{H}_{6^{\prime}}\right), 7.31\left(1 \mathrm{H}, \mathrm{d}, J=9.3 \mathrm{~Hz}, \mathrm{H}_{8}\right), 7.24\left(1 \mathrm{H}, \mathrm{d}, J=2.9 \mathrm{~Hz}, \mathrm{H}_{5}\right), 7.17$ $\left(1 \mathrm{H}, \mathrm{dd}, J=2.9\right.$ and $\left.9.2 \mathrm{~Hz}, \mathrm{H}_{7}\right), 5.68\left(2 \mathrm{H}, \mathrm{s}, \mathrm{H}_{1 \mathrm{a}}\right), 3.80(3 \mathrm{H}, \mathrm{s}$, $\left.\mathrm{CH}_{3}\right)$ ppm; $\delta_{\mathrm{C}}\left(101 \mathrm{MHz}, \mathrm{DMSO}-\mathrm{d}_{6}\right): 178.1,160.1,154.6,146.6$, 144.7, 136.9, 134.5, 133.3, 127.7, 124.9, 123.8, 121.0, 120.1, 116.4, $111.8,55.4,44.8 \mathrm{ppm} ; v_{\max }\left(\right.$ neat, $\left.\mathrm{cm}^{-1}\right): 3215(\mathrm{NH}), 3155(\mathrm{NH}), 1636$ $(\mathrm{C}=\mathrm{O}), 1511(\mathrm{C}=\mathrm{N}), 1206(\mathrm{C}=\mathrm{S}), 860(\mathrm{C}-\mathrm{S}) ; \mathrm{HRMS}(\mathrm{ESI}) \mathrm{m} / \mathrm{z}$ calcd for $\mathrm{C}_{19} \mathrm{H}_{17} \mathrm{~N}_{5} \mathrm{O}_{4} \mathrm{~S}: 411.1001$, found $412.0810[\mathrm{M}+\mathrm{H}]^{+}$; Anal. calcd for $\mathrm{C}_{19} \mathrm{H}_{17} \mathrm{~N}_{5} \mathrm{O}_{4} \mathrm{~S}$ : C, 55.47; H, 4.16; N, 17.02; S, $7.79 \%$. Found: C, 55.32; H, 4.28; N, 17.08; S, $7.97 \%$.

(E)-2-((1-Benzyl-6-methyl-2-oxo-1,2-dihydroquinolin-3-yl)methylene)hydrazinecarbothioamide (9i): $38 \%$ yield; yellow solid; mp 236-238 $\left.{ }^{\circ} \mathrm{C} ; \delta_{\mathrm{H}}(400 \mathrm{MHz} \text {; DMSO-d })_{6}\right): 11.7(1 \mathrm{H}, \mathrm{s}, \mathrm{N}(11) \mathrm{H}), 8.79$ $\left(1 \mathrm{H}, \mathrm{s}, \mathrm{H}_{9}\right), 8.38\left(1 \mathrm{H}, \mathrm{s}, \mathrm{H}_{4}\right), 8.33(1 \mathrm{H}$, br s, $\mathrm{NHH}), 8.14(1 \mathrm{H}$, br s, $\mathrm{NHH}), 7.51\left(1 \mathrm{H}, \mathrm{d}, J=1.5 \mathrm{~Hz}, \mathrm{H}_{5}\right), 7.35(1 \mathrm{H}, \mathrm{dd}, J=1.6$ and $8.6 \mathrm{~Hz}$, $\left.\mathrm{H}_{7}\right), 7.32-7.27\left(3 \mathrm{H}, \mathrm{m}, \mathrm{H}_{8}, \mathrm{H}_{2^{\prime}}\right.$ and $\left.\mathrm{H}_{6^{\prime}}\right), 7.25-7.17\left(3 \mathrm{H}, \mathrm{m}, \mathrm{H}_{3^{\prime}}, \mathrm{H}_{4^{\prime}}\right.$ and $\left.\mathrm{H}_{5^{\prime}}\right), 5.54\left(2 \mathrm{H}, \mathrm{s}, \mathrm{H}_{1 \mathrm{a}}\right), 2.34\left(1 \mathrm{H}, \mathrm{s}, \mathrm{CH}_{3}\right) \mathrm{ppm} ; \delta_{\mathrm{C}}(101 \mathrm{MHz}$, DMSO-d d $_{6}: 178.1,160.5,137.1,137.0,136.6,134.5,132.5,131.7$, 129.1, 128.6, 127.0, 126.5, 124.5, 120.1, 115.2, 44.9, 20.0 ppm; $v_{\max }\left(\right.$ neat, $\left.\mathrm{cm}^{-1}\right)$ : $3191(\mathrm{NH}), 3151(\mathrm{NH}), 1633(\mathrm{C}=\mathrm{O}), 1522(\mathrm{C}=\mathrm{N})$, $1203(\mathrm{C}=\mathrm{S}), 835$ (C-S); HRMS (ESI) $\mathrm{m} / z$ (calcd for $\mathrm{C}_{19} \mathrm{H}_{18} \mathrm{~N}_{4} \mathrm{OS}$ : 350.1201, found 351.1273 $[\mathrm{M}+\mathrm{H}]^{+}$; Anal. calcd for $\mathrm{C}_{19} \mathrm{H}_{18} \mathrm{~N}_{4} \mathrm{OS} \cdot 0.25 \mathrm{H}_{2} \mathrm{O}: \mathrm{C}, 64.29 ; \mathrm{H}, 5.25 ; \mathrm{N}, 15.78 ; \mathrm{S}, 9.03 \%$. Found: C, 64.10; H, 5.24; N, 15.78; S, 9.22\%.

(E)-2-((6-Methyl-1-(4-nitrobenzyl)-2-oxo-1,2-dihydroquinolin-3-yl) methylene)hydrazinecarbothioamide (9j): $44 \%$ yield; yellow solid; mp 241-243 ${ }^{\circ} \mathrm{C} ; \delta_{\mathrm{H}}\left(400 \mathrm{MHz} ; \mathrm{DMSO}-\mathrm{d}_{6}\right): 11.7(1 \mathrm{H}, \mathrm{s}, \mathrm{N}(11) \mathrm{H})$, $8.83\left(1 \mathrm{H}, \mathrm{s}, \mathrm{H}_{9}\right), 8.37\left(1 \mathrm{H}, \mathrm{s}, \mathrm{H}_{4}\right), 8.35(1 \mathrm{H}, \mathrm{br} \mathrm{s}, \mathrm{NHH}), 8.17-8.16$ $\left(2 \mathrm{H}, \mathrm{m}, \mathrm{H}_{3^{\prime}}\right.$ and $\left.\mathrm{H}_{5^{\prime}}\right), 8.12(1 \mathrm{H}$, br s, $\mathrm{NHH}), 7.52(1 \mathrm{H}, \mathrm{d}, J=1.3 \mathrm{~Hz}$, $\left.\mathrm{H}_{5}\right), 7.47-7.43\left(2 \mathrm{H}, \mathrm{m}, \mathrm{H}_{2^{\prime}}\right.$ and $\left.\mathrm{H}_{6^{\prime}}\right), 7.37(1 \mathrm{H}, \mathrm{dd}, J=1.7$ and $8.7 \mathrm{~Hz}$, $\left.\mathrm{H}_{7}\right), 7.27\left(1 \mathrm{H}, \mathrm{d}, J=8.7 \mathrm{~Hz}, \mathrm{H}_{8}\right)$ ppm; $\delta_{\mathrm{C}}\left(101 \mathrm{MHz}, \mathrm{DMSO}-\mathrm{d}_{6}\right)$ : 178.1, 160.5, 146.6, 144.7, 136.9, 136.8, 134.8, 132.7, 132.0, 129.3, $127.7,124.5,123.8,120.2,114.9,44.7,20.0 \mathrm{ppm} ; v_{\max }\left(\right.$ neat, $\left.\mathrm{cm}^{-1}\right)$ : $3215(\mathrm{NH}), 3150(\mathrm{NH}), 1638(\mathrm{C}=\mathrm{O}), 1520(\mathrm{C}=\mathrm{N}), 1205(\mathrm{C}=\mathrm{S}), 850$ (C-S); HRMS (ESI) $\mathrm{m} / \mathrm{z}$ calcd for $\mathrm{C}_{19} \mathrm{H}_{17} \mathrm{~N}_{5} \mathrm{O}_{3} \mathrm{~S}$ : 395.1052, found
$396.1135[\mathrm{M}+\mathrm{H}]^{+}$; Anal. calcd for $\mathrm{C}_{19} \mathrm{H}_{17} \mathrm{~N}_{5} \mathrm{O}_{3} \mathrm{~S} \cdot 0.25 \mathrm{H}_{2} \mathrm{O}$ : C, 57.06 ; H, 4.41; N, 17.51; S, 8.02 \%. Found: C, 56.78; H, 3.98; N, 17.11; S, $7.98 \%$.

(E)-2-((2-Oxo-1-(prop-2-yn-1-yl)-1,2-dihydroquinolin-3-yl)methylene)hydrazinecarbothioamide (9k): $59 \%$ yield; yellow solid; $\mathrm{mp}$ $258{ }^{\circ} \mathrm{C}$ (Decomposed); $\delta_{\mathrm{H}}\left(400 \mathrm{MHz} ; \mathrm{DMSO}-\mathrm{d}_{6}\right): 11.7(1 \mathrm{H}, \mathrm{s}$, $\mathrm{N}(11) \mathrm{H}), 8.83\left(1 \mathrm{H}, \mathrm{s}, \mathrm{H}_{9}\right), 8.36(1 \mathrm{H}, \mathrm{br} \mathrm{s}, \mathrm{NHH}), 8.32\left(1 \mathrm{H}, \mathrm{s}, \mathrm{H}_{4}\right), 8.14$ $(1 \mathrm{H}$, br s, $\mathrm{NHH}), 7.72\left(1 \mathrm{H}, \mathrm{m}, \mathrm{H}_{7}\right.$ and $\left.\mathrm{H}_{8}\right), 7.61(1 \mathrm{H}, \mathrm{d}, J=8.5 \mathrm{~Hz}$, $\left.\mathrm{H}_{5}\right), 7.36\left(1 \mathrm{H}, \mathrm{t}, J=7.95 \mathrm{~Hz}, \mathrm{H}_{6}\right), 5.13\left(2 \mathrm{H}, \mathrm{d}, J=1.9 \mathrm{~Hz}, \mathrm{H}_{1 \mathrm{a}}\right), 3.29$ $\left(1 \mathrm{H}, \mathrm{t}, J=2.2 \mathrm{~Hz}, \mathrm{H}_{2 \mathrm{c}}\right) ; \delta_{\mathrm{C}}\left(101 \mathrm{MHz}, \mathrm{DMSO}-\mathrm{d}_{6}\right): 178.1,159.6$, 138.2, 136.7, 136.6, 131.4, 129.6, 124.4, 123.0, 120.1, 115.1, 78.6, 74.6, $31.4 \mathrm{ppm} ; v_{\max }\left(\right.$ neat, $\left.\mathrm{cm}^{-1}\right): 3272(\mathrm{NH}), 3156(\mathrm{NH}), 1645(\mathrm{C}=\mathrm{O})$, $1532(\mathrm{C}=\mathrm{S}), 846$ (C-S); HRMS $m / z$ calcd for $\mathrm{C}_{14} \mathrm{H}_{12} \mathrm{~N}_{4} \mathrm{OS} 284.0732$, found: $285.0819[\mathrm{M}+\mathrm{H}]^{+}$; Anal. calcd for $\mathrm{C}_{14} \mathrm{H}_{12} \mathrm{~N}_{4} \mathrm{OS} \cdot 0.125 \mathrm{H}_{2} \mathrm{O}$ : C, 58.67; H, 4.31; N, 19.55; S, 11.19 \%. Found: C, 58.69; H, 3.81; $\mathrm{N}, 19.38 ; \mathrm{S}, 11.15 \%$.

(E)-2-((6-methoxy-2-oxo-1-(prop-2-ynyl)-1,2-dihydroquinolin-3-yl) methylene)hydrazinecarbothioamide (91): $56 \%$ yield; yellow solid; mp $232{ }^{\circ} \mathrm{C}$ (Decomposed); $\delta_{\mathrm{H}}\left(400 \mathrm{MHz} ; \mathrm{DMSO}-\mathrm{d}_{6}\right): 11.6(1 \mathrm{H}, \mathrm{s}$, $\mathrm{N}(11) \mathrm{H}), 8.70\left(1 \mathrm{H}, \mathrm{s}, \mathrm{H}_{9}\right), 8.30(1 \mathrm{H}, \mathrm{br} \mathrm{s}, \mathrm{NHH}), 8.32\left(1 \mathrm{H}, \mathrm{s}, \mathrm{H}_{4}\right), 8.09$ $\left(1 \mathrm{H}\right.$, br s, NHH), $7.46\left(1 \mathrm{H}, \mathrm{d}, J=9.3 \mathrm{~Hz}, \mathrm{H}_{8}\right), 7.25(1 \mathrm{H}, \mathrm{dd}, J=2.9$ and $\left.9.2 \mathrm{~Hz}_{1} \mathrm{H}_{7}\right), 7.15\left(1 \mathrm{H}, \mathrm{d}, J=2.9 \mathrm{~Hz}, \mathrm{H}_{5}\right), 5.03(2 \mathrm{H}, \mathrm{d}, J=2.1 \mathrm{~Hz}$, $\left.\mathrm{H}_{1 \mathrm{a}}\right), 3.75\left(3 \mathrm{H}, \mathrm{s}, \mathrm{CH}_{3}\right), 3.18\left(1 \mathrm{H}, \mathrm{t}, J=2.2 \mathrm{~Hz}, \mathrm{H}_{2 \mathrm{c}}\right) \mathrm{ppm}$; $\delta_{\mathrm{C}}\left(101 \mathrm{MHz}, \mathrm{DMSO}-\mathrm{d}_{6}\right): 178.1,159.1,154.6,136.7,134.3,132.8$, 124.8, 120.8, 120.1, 116.5, 110.9, 78.8, 74.5, 55.4, 31.4 ppm; $v_{\max }\left(\right.$ neat, $\left.\mathrm{cm}^{-1}\right): 3258(\mathrm{NH}), 3172(\mathrm{NH}), 1635(\mathrm{C}=\mathrm{O}), 1203(\mathrm{C}=\mathrm{S})$, $1521(\mathrm{C}=\mathrm{N}), 849$ (C-S); HRMS (ESI) $\mathrm{m} / z$ calcd for $\mathrm{C}_{15} \mathrm{H}_{14} \mathrm{~N}_{4} \mathrm{O}_{2} \mathrm{~S}$ : 298.0888, found $299.0805[\mathrm{M}+\mathrm{H}]^{+}$; Anal. calcd for $\mathrm{C}_{15} \mathrm{H}_{14} \mathrm{~N}_{4} \mathrm{O}_{2} \mathrm{~S}$ : C, 56.94; H, 5.10; N, 17.71; S, 10.14 \%. Found: C, 56.52; H, 5.19; $\mathrm{N}, 17.58 ; \mathrm{S}, 10.33 \%$.

(E)-2-((6-Methyl-2-oxo-1-(prop-2-yn-1-yl)-1,2-dihydroquinolin-3-yl) methylene)hydrazinecarbothioamide $(9 \mathrm{~m})$ : $60 \%$ yield; yellow solid; mp $244{ }^{\circ} \mathrm{C}$ (Decomposed); $\delta_{\mathrm{H}}\left(400 \mathrm{MHz} ;\right.$ DMSO-d $\left.\mathrm{d}_{6}\right): 11.6(1 \mathrm{H}, \mathrm{s}$, $\mathrm{N}(11) \mathrm{H}), 8.75\left(1 \mathrm{H}, \mathrm{s}, \mathrm{H}_{9}\right), 8.35(1 \mathrm{H}, \mathrm{br} \mathrm{s}, \mathrm{NHH}), 8.32\left(1 \mathrm{H}, \mathrm{s}, \mathrm{H}_{4}\right), 8.07$ $\left(1 \mathrm{H}\right.$, br s, NHH) $, 7.55\left(1 \mathrm{H}, \mathrm{d}, J=9.3 \mathrm{~Hz}, \mathrm{H}_{8}\right), 734(1 \mathrm{H}, \mathrm{dd}, J=2.9$ and $\left.9.2 \mathrm{~Hz}, \mathrm{H}_{7}\right), 7.23\left(1 \mathrm{H}, \mathrm{d}, J=2.9 \mathrm{~Hz}, \mathrm{H}_{5}\right), 5.11(1 \mathrm{H}, \mathrm{d}, J=2.1 \mathrm{~Hz}$, $\left.\mathrm{H}_{1 \mathrm{a}}\right), 3.25\left(1 \mathrm{H}, \mathrm{t}, J=2.3 \mathrm{~Hz}, \mathrm{H}_{2 \mathrm{c}}\right), 2.39\left(3 \mathrm{H}, \mathrm{s}, \mathrm{CH}_{3}\right)$ ppm; $\delta_{\mathrm{C}}\left(101 \mathrm{MHz}, \mathrm{DMSO}-\mathrm{d}_{6}\right): 178.1,159.4,136.8,136.2,134.6,132.6$, 132.1, 129.1, 124.3, 120.0, 115.0, 78.8, 74.6, 31.3, 20.1 ppm; $v_{\max }\left(\right.$ neat, $\left.\mathrm{cm}^{-1}\right): 3279(\mathrm{NH}), 3183(\mathrm{NH}), 1627(\mathrm{C}=\mathrm{O}), 1522(\mathrm{C}=\mathrm{N})$, $1206(\mathrm{C}=\mathrm{S}), 836(\mathrm{C}-\mathrm{S})$; HRMS (ESI) $\mathrm{m} / \mathrm{z}$ calcd for $\mathrm{C}_{15} \mathrm{H}_{14} \mathrm{~N}_{4} \mathrm{OS}$ : 314.0837, found $315.0927[\mathrm{M}+\mathrm{H}]^{+}$; Anal. calcd for $\mathrm{C}_{15} \mathrm{H}_{14} \mathrm{~N}_{4} \mathrm{OS} \cdot 0.75 \mathrm{CH}_{3} \mathrm{OH} \cdot 1 \mathrm{H}_{2} \mathrm{O}: \mathrm{C}, 55.57, \mathrm{H} ; 5.63, \mathrm{~N} ; 16.46$, S; $9.42 \%$. Found; C; 55.32, H; 5.58, N; 16.8, S; $9.98 \%$.

(E)-2-((1-(2-((7-Chloroquinolin-4-yl)amino)ethyl)-2-oxo-1,2-dihydro quinolin-3-yl)methylene)hydrazinecarbothioamide (9n): 68 yield; yellow solid; $\mathrm{mp} 235-237^{\circ} \mathrm{C} ; \delta_{\mathrm{H}}\left(400 \mathrm{MHz} ; \mathrm{DMSO}-\mathrm{d}_{6}\right): 12.6(1 \mathrm{H}, \mathrm{s}$, $\mathrm{NH}), 8.80\left(1 \mathrm{H}, \mathrm{s}, \mathrm{H}_{9}\right), 8.44\left(1 \mathrm{H}, \mathrm{d}, J=5.3 \mathrm{~Hz}, \mathrm{H}_{2}\right), 8.35\left(1 \mathrm{H}, \mathrm{s}_{1} \mathrm{H}_{4}\right)$, $8.33(1 \mathrm{H}$, br s, NHH) $8.11(1 \mathrm{H}$, brs, NHH), $8.06(1 \mathrm{H}, \mathrm{d}, J=9.1 \mathrm{~Hz}$, $\left.\mathrm{H}_{5^{\prime}}\right), 7.97\left(1 \mathrm{H}, \mathrm{d}, J=1.9 \mathrm{~Hz}, \mathrm{H}_{8^{\prime}}\right), 7.71\left(1 \mathrm{H}, \mathrm{d}, J=7.6 \mathrm{~Hz}, \mathrm{H}_{5}\right), 7.60$ $\left(1 \mathrm{H}, \mathrm{t}, J=8.6 \mathrm{~Hz}_{1} \mathrm{H}_{7}\right), 7.57-7.47\left(2 \mathrm{H}, \mathrm{m}, \mathrm{H}_{5}\right.$ and $\left.\mathrm{NH}\right), 7.45(1 \mathrm{H}, \mathrm{dd}$, $\mathrm{J}=1.9$ and $\left.9.1 \mathrm{~Hz}, \mathrm{H}_{6}\right), 7.28\left(1 \mathrm{H}, \mathrm{t}, J=7.4 \mathrm{~Hz}, \mathrm{H}_{6}\right), 6.72(1 \mathrm{H}, \mathrm{d}, J=$ $\left.5.4 \mathrm{~Hz}, \mathrm{H}_{3^{\prime}}\right), 4.56\left(2 \mathrm{H}, \mathrm{t}, J=6.6 \mathrm{~Hz}, \mathrm{CH}_{2}\right), 4.09(2 \mathrm{H}, \mathrm{q}, J=6.0,7.5$ and $\left.8.8 \mathrm{~Hz}, \mathrm{CH}_{2}\right)$ ppm; $\delta_{\mathrm{C}}\left(101 \mathrm{MHz}, \mathrm{DMSO}-\mathrm{d}_{6}\right): 178.7,161.2$, $152.5,150.5,149.5,139.7,137.4,133.4,131.9,130.2,128.0,124.9$, 124.8, 124.7, 124.2, 123.2, 120.7, 114.9, 99.1, 49.1, 41.1 ppm; $v_{\max }\left(\right.$ neat, $\left.\mathrm{cm}^{-1}\right): 3234(\mathrm{NH}), 3150(\mathrm{NH}), 1633(\mathrm{C}=\mathrm{O}), 1515(\mathrm{C}=\mathrm{N})$, $1204(\mathrm{C}=\mathrm{S}), 844(\mathrm{C}-\mathrm{S}), 716(\mathrm{C}-\mathrm{Cl})$; HRMS (ESI) $\mathrm{m} / \mathrm{z}$ calcd for $\mathrm{C}_{22} \mathrm{H}_{19} \mathrm{ClN}_{6} \mathrm{OS}: 450.1030$, found $451.1099[\mathrm{M}+\mathrm{H}]^{+}$; Anal. calcd. for $\mathrm{C}_{22} \mathrm{H}_{19} \mathrm{ClN}_{6} \mathrm{OS}$ : C, 58.60; $\mathrm{H}, 4.25 ; \mathrm{N}, 18.64 ; \mathrm{S}, 7.11 \%$, Found: C, 59.21; H, 4.22; N, 18.55; S, $6.99 \%$. 
(E)-2-((1-(3-((7-Chloroquinolin-4-yl)amino)propyl)-2-oxo-1,2-dihydroquinolin-3-yl)methylene)hydrazinecarbothioamide (9o): $48 \%$ yield; amorphous yellow solid; $\mathrm{mp} 240-242{ }^{\circ} \mathrm{C} ; \delta_{\mathrm{H}}(400 \mathrm{MHz}$; DMSO-d $\left.)_{6}\right): 11.6(1 \mathrm{H}, \mathrm{s}, \mathrm{N}(11) \mathrm{H}), 8.78\left(1 \mathrm{H}, \mathrm{s}, \mathrm{H}_{9}\right), 8.38(1 \mathrm{H}, \mathrm{d}, J=$ $\left.5.3 \mathrm{~Hz}, \mathrm{H}_{2^{\prime}}\right), 8.34\left(1 \mathrm{H}, \mathrm{s}, \mathrm{H}_{4}\right), 8.32(1 \mathrm{H}, \mathrm{br} \mathrm{s}, \mathrm{NHH}), 8.25(1 \mathrm{H}, \mathrm{d}, J=$ $\left.9.0 \mathrm{~Hz}_{2} \mathrm{H}_{5^{\prime}}\right), 8.10(1 \mathrm{H}, \mathrm{br} \mathrm{s}, \mathrm{NHH}), 7.79\left(1 \mathrm{H}, \mathrm{d}, J=1.8 \mathrm{~Hz}, \mathrm{H}_{8^{\prime}}\right), 7.72$ $\left(1 \mathrm{H}, \mathrm{d}, J=1.0\right.$ and $\left.7.7 \mathrm{~Hz}, \mathrm{H}_{8}\right), 7.63\left(1 \mathrm{H}, \mathrm{d}, J=0.7\right.$ and $\left.8.6 \mathrm{~Hz}, \mathrm{H}_{5}\right)$, $7.55\left(1 \mathrm{H}, \mathrm{ddd}, J=1.0,7.2\right.$ and $\left.9.0 \mathrm{~Hz}, \mathrm{H}_{6}\right), 7.46(1 \mathrm{H}, \mathrm{dd}, J=1.8$ and $\left.\left.9.0 \mathrm{~Hz}, \mathrm{H}_{6^{\prime}}\right), 7.391 \mathrm{H}, \mathrm{s}, \mathrm{NH}\right), 7.30(1 \mathrm{H}, \mathrm{ddd}, J=0.7,7.2$ and $8.6 \mathrm{~Hz}$ $\left.\mathrm{H}_{7}\right), 6.50\left(1 \mathrm{H}, \mathrm{d}, J=5.4 \mathrm{~Hz}, \mathrm{H}_{3^{\prime}}\right), 4.47-4.39\left(2 \mathrm{H}, \mathrm{m}, \mathrm{H}_{1^{\prime}}\right), 3.45-3.41$ $\left(2 \mathrm{H}, \mathrm{m}, \mathrm{H}_{3^{\prime}}\right), 2.10-2.01\left(2 \mathrm{H}, \mathrm{m}, \mathrm{H}_{2^{\prime}}\right) \mathrm{ppm} ; \delta_{\mathrm{C}}\left(101 \mathrm{MHz}, \mathrm{DMSO}-\mathrm{d}_{6}\right)$ : $178.6,165.3,160.6,152.4,150.5,139.3,137.6,133.9,130.2,128.0$, $124.9,124.9,124.7,124.6,124.4,124.4,123.1,120.7,118.0,115.1$, 99.2, 40.8, 39.3, 26.7 ppm; $v_{\max }\left(\right.$ neat, $\left.\mathrm{cm}^{-1}\right): 3325(\mathrm{NH}), 3234(\mathrm{NH})$, $1641(\mathrm{C}=\mathrm{O}), 1505(\mathrm{C}=\mathrm{N}), 1194(\mathrm{C}=\mathrm{S}), 854(\mathrm{C}-\mathrm{S}), 712(\mathrm{C}-\mathrm{Cl})$; HRMS (ESI) $\mathrm{m} / \mathrm{z}$ calcd for $\mathrm{C}_{23} \mathrm{H}_{21} \mathrm{ClN}_{6} \mathrm{OS}$ : 464.1186, found $465.1268[\mathrm{M}+\mathrm{H}]^{+}$; Anal. calcd for $\mathrm{C}_{23} \mathrm{H}_{21} \mathrm{ClN}_{6} \mathrm{OS}$ : C, 59.41; H, 4.55; N, 18.07; S, 6.90 \%. Found: C, 59.82; H, 4.44; N, 17.93; S, $6.63 \%$.

(E)-2-((1-((1-Benzyl-1H-1,2,3-triazol-4-yl)methyl)-2-oxo-1,2-dihydroquinolin-3-yl)methylene)hydrazinecarbothioamide (9p): $45 \%$ yield; yellow solid; $\mathrm{mp} 240-242{ }^{\circ} \mathrm{C} ; \delta_{\mathrm{H}}\left(400 \mathrm{MHz}\right.$; DMSO- $\left.\mathrm{d}_{6}\right): 11.7$ $(1 \mathrm{H}, \mathrm{s}, \mathrm{N}(11) \mathrm{H}), 8.81\left(1 \mathrm{H}, \mathrm{s}, \mathrm{H}_{9}\right), 8.35\left(1 \mathrm{H}, \mathrm{s}, \mathrm{H}_{4}\right), 8.32(1 \mathrm{H}, \mathrm{br} \mathrm{s}$, $\mathrm{NHH}), 8.11(1 \mathrm{H}$, br s, $\mathrm{NHH}), 8.08\left(1 \mathrm{H}, \mathrm{s}, \mathrm{H}_{5^{\prime}}\right), 7.73-7.70\left(2 \mathrm{H}, \mathrm{m}, \mathrm{H}_{2}\right.$ and $\left.\mathrm{H}_{6}\right), 7.38\left(1 \mathrm{H}\right.$, ddd, $J=1.2$ and $\left.7.3,9.0 \mathrm{~Hz}, \mathrm{H}_{6}\right), 7.37-7.24(6 \mathrm{H}$, $\mathrm{m}, \mathrm{H}_{5}, \mathrm{H}_{7}, \mathrm{H}_{8}, \mathrm{H}_{5^{\prime}}, \mathrm{H}_{4^{\prime}}$ and $\left.\mathrm{H}_{3^{\prime}}\right), 5.55\left(2 \mathrm{H}, \mathrm{s}, \mathrm{H}_{4 \mathrm{a}}\right), 5.51(2 \mathrm{H}, \mathrm{s}$, $\left.\mathrm{H}_{1 \mathrm{a}}\right)$ ppm; $\delta_{\mathrm{C}}\left(101 \mathrm{MHz}, \mathrm{DMSO}-\mathrm{d}_{6}\right): 178.1,160.2,142.8,138.9$, 136.9, 135.4, 134.7, 131.3, 129.6, 128.7, 128.1, 127.9, 124.5, 123.7, 122.7, 120.1, 115.1, 52.7, 37.7 ppm; $v_{\max }\left(\right.$ neat, $\left.\mathrm{cm}^{-1}\right): 3215(\mathrm{NH})$, $3156(\mathrm{NH}), 1634(\mathrm{C}=\mathrm{O}), 1524(\mathrm{C}=\mathrm{N}), 1567(\mathrm{~N}=\mathrm{N}), 1203(\mathrm{C}=\mathrm{S})$, 843 (C-S); HRMS (ESI) $\mathrm{m} / z$ calcd for $\mathrm{C}_{21} \mathrm{H}_{19} \mathrm{~N}_{7} \mathrm{OS}: 417.1372$, found $418.1455[\mathrm{M}+\mathrm{H}]^{+}$; Anal. calcd for $\mathrm{C}_{21} \mathrm{H}_{19} \mathrm{~N}_{7} \mathrm{OS} \cdot 0.125 \mathrm{H}_{2} \mathrm{O}$ : C, 60.09; H, 4.62; N, 23.36; S, $7.64 \%$. Found: C, 60.04; H, 4.52; N, 22.99; S, $7.34 \%$.

(E)-2-((1-((1-(4-Nitrobenzyl)-1H-1,2,3-triazol-4-yl)methyl)-2-oxo-1, 2-dihydroquinolin-3-yl)methylene)hydrazinecarbothioamide (9q): $55 \%$ yield; yellow solid; $\mathrm{mp} 258-260^{\circ} \mathrm{C} ; \delta_{\mathrm{H}}(400 \mathrm{MHz}$; DMSO-d $)$ : $11.7(1 \mathrm{H}, \mathrm{s}, \mathrm{N}(11) \mathrm{H}), 8.80\left(1 \mathrm{H}, \mathrm{s}, \mathrm{H}_{9}\right), 8.35\left(1 \mathrm{H}, \mathrm{s}, \mathrm{H}_{4}\right), 8.33(1 \mathrm{H}, \mathrm{br} \mathrm{s}$, $\mathrm{NHH}), 8.22-8.18\left(2 \mathrm{H}, \mathrm{m}, \mathrm{H}_{3^{\prime \prime}}\right.$ and $\left.\mathrm{H}_{5^{\prime \prime}}\right), 8.17\left(1 \mathrm{H}, \mathrm{s}, \mathrm{H}_{5^{\prime}}\right), 8.11(1 \mathrm{H}, \mathrm{s}$, $\mathrm{NH} H), 7.74-7.70\left(2 \mathrm{H}, \mathrm{m}, \mathrm{H}_{5}\right.$ and $\left.\mathrm{H}_{8}\right), 7.62(1 \mathrm{H}, \mathrm{ddd}, J=1.3,7.2$ and $\left.8.9 \mathrm{~Hz}, \mathrm{H}_{6}\right), 7.52-7.47\left(2 \mathrm{H}, \mathrm{m}, \mathrm{H}_{2^{\prime \prime}}\right.$ and $\left.\mathrm{H}_{6^{\prime \prime}}\right), 7.31(1 \mathrm{H}, \mathrm{ddd}, J=$ $0.5,7.2$ and $\left.8.4 \mathrm{~Hz}, \mathrm{H}_{7}\right), 5.71\left(2 \mathrm{H}, \mathrm{s}, \mathrm{H}_{4 \mathrm{a}}\right), 5.58\left(2 \mathrm{H}, \mathrm{s}, \mathrm{H}_{\mathrm{aa}}\right) \mathrm{ppm}$; $\delta_{\mathrm{C}}\left(101 \mathrm{MHz}, \mathrm{DMSO}-\mathrm{d}_{6}\right): 178.1,160.3,147.3,143.4,143.1,138.9$, $136.9,134.8,131.5,129.2,124.6,124.3,123.9,122.9,120.2,51.9$ ppm; $v_{\max }\left(\right.$ neat, $\left.\mathrm{cm}^{-1}\right): 3361(\mathrm{NH}), 3255(\mathrm{NH}), 1635(\mathrm{C}=\mathrm{O}), 1514(\mathrm{C}=\mathrm{N})$, $1564(\mathrm{~N}=\mathrm{N}), 1202(\mathrm{C}=\mathrm{S}), 847(\mathrm{C}-\mathrm{S})$; HRMS (ESI) $\mathrm{m} / \mathrm{z}$ calcd for $\mathrm{C}_{21} \mathrm{H}_{18} \mathrm{~N}_{8} \mathrm{O}_{3} \mathrm{~S}$ : 462.1223, found $463.1306[\mathrm{M}+\mathrm{H}]^{+}$; Anal. calcd for $\mathrm{C}_{21} \mathrm{H}_{18} \mathrm{~N}_{8} \mathrm{O}_{3} \mathrm{~S} \cdot 0.5 \mathrm{H}_{2} \mathrm{O}: \mathrm{C}, 53.50 ; \mathrm{H}, 4.06 ; \mathrm{N}, 23.77 ; \mathrm{S}, 6.80 \%$. Found: C, 53.33; H, 3.77; N, 23.95; S, $6.58 \%$.

(E)-2-((1-((1-(7-Chloroquinolin-4-yl)-1H-1,2,3-triazol-4-yl)methyl)2-oxo-1,2-dihydroquinolin-3-yl)methylene) hydrazinecarbothioamide (9r): $46 \%$ yield; amorphous yellow solid; mp 251-253 ${ }^{\circ} \mathrm{C}$; $\delta_{\mathrm{H}}\left(300 \mathrm{MHz} ; \mathrm{DMSO}-\mathrm{d}_{6}\right): 11.7(1 \mathrm{H}, \mathrm{s}, \mathrm{N}(11) \mathrm{H}), 9.10(1 \mathrm{H}, \mathrm{d}, J=4.6$ $\left.\mathrm{Hz}, \mathrm{H}_{2^{\prime \prime}}\right), 8.84\left(1 \mathrm{H}, \mathrm{s}, \mathrm{H}_{9}\right), 8.77\left(1 \mathrm{H}, \mathrm{s}, \mathrm{H}_{5^{\prime}}\right), 8.38\left(1 \mathrm{H}, \mathrm{s}, \mathrm{H}_{4}\right), 8.33(1 \mathrm{H}$, br s, NHH), $8.26\left(1 \mathrm{H}, \mathrm{d}, J=1.8 \mathrm{~Hz}, \mathrm{H}_{8^{\prime}}\right), 8.13(1 \mathrm{H}, \mathrm{br} \mathrm{s}, \mathrm{NHH}), 7.97$ $\left(1 \mathrm{H}, \mathrm{d}, J=8.9 \mathrm{~Hz}, \mathrm{H}_{5^{\prime}}\right), 7.85-7.72\left(4 \mathrm{H}, \mathrm{m}, \mathrm{H}_{5}, \mathrm{H}_{8}, \mathrm{H}_{3^{\prime}}\right.$ and $\left.\mathrm{H}_{6^{\prime}}\right), 7.67$ $\left(1 \mathrm{H}, \mathrm{ddd}, J=1.3,7.0\right.$ and $\left.8.9 \mathrm{~Hz}, \mathrm{H}_{6}\right), 7.34(1 \mathrm{H}, \mathrm{ddd}, J=0.6,7.0,8.6$ $\left.\mathrm{Hz}_{1} \mathrm{H}_{7}\right), 5.76\left(2 \mathrm{H}, \mathrm{s}, \mathrm{H}_{4 \mathrm{a}}\right)$ ppm; $\delta_{\mathrm{C}}\left(75 \mathrm{MHz}, \mathrm{DMSO}-\mathrm{d}_{6}\right): 178.1$, $160.2,152.9,149.3,143.5,140.2,139.0,136.9,136.3,134.8,131.4$, $129.7,128.9,128.1,125.9,125.4,124.6,122.8,120.2,117.0,115.2$, 37.5 ppm; $v_{\max }\left(\right.$ neat, $\left.\mathrm{cm}^{-1}\right): 3358(\mathrm{NH}), 3233(\mathrm{NH}), 1638(\mathrm{C}=\mathrm{O})$, $1517(\mathrm{C}=\mathrm{N}), 1568(\mathrm{~N}=\mathrm{N}), 1516(\mathrm{C}=\mathrm{N}), 1205(\mathrm{C}=\mathrm{S}), 851(\mathrm{C}-\mathrm{S})$;
HRMS (ESI) $m / z$ calcd for $\mathrm{C}_{23} \mathrm{H}_{17} \mathrm{ClN}_{8} \mathrm{OS}$ : 488.0935, found $489.1011[\mathrm{M}+\mathrm{H}]^{+}$. Anal. calcd for $\mathrm{C}_{23} \mathrm{H}_{17} \mathrm{ClN}_{8} \mathrm{OS} \cdot 0.25 \mathrm{H}_{2} \mathrm{O}$ : C, 55.98; H, 3.57; N, 22.71; S, 6.50 \%. Found: C, 55.81; H, 3.46; $\mathrm{N}, 23.01 ; \mathrm{S}, 6.62 \%$.

\subsection{Biological Testing and Growth Inhibition Assays}

\subsubsection{In Vitro Antitrypanosomal and Cytotoxicity Assays}

The HeLa cells (Cellonex) were cultured using method described by Oderinlo et al. and Adeyemi et al. ${ }^{30,31}$ Trypanosoma brucei brucei 427 trypomastigotes were cultured in Iscove's Modified Dulbecco's Medium (IMDM; Lonza) supplemented with $10 \%$ fetal calf serum, HMI-9 supplement, ${ }^{32}$ hypoxanthine and penicillin/streptomycin at $37{ }^{\circ} \mathrm{C}$ in a $5 \% \mathrm{CO}_{2}$ incubator. Serial dilutions of test compounds were incubated with the parasites in 96-well plates for $24 \mathrm{~h}$ and residual parasite viability in the wells determined by adding $20 \mu \mathrm{L}$ of $0.54 \mathrm{mM}$ resazurin in phosphate buffered saline (PBS) and incubating for an additional $24 \mathrm{~h}$. Reduction of resazurin to resorufin by viable parasites was assessed by fluorescence readings (excitation $560 \mathrm{~nm}$, emission $590 \mathrm{~nm}$ ) in a Spectramax M3 plate reader. Fluorescence readings were converted to $\%$ parasite viability relative to the average readings obtained from untreated control wells. $\mathrm{IC}_{50}$ values were determined by plotting $\%$ viability $v$ s. $\log [\mathrm{com}-$ pound] and performing non-linear regression using GraphPad Prism (v. 5.02) software. ${ }^{30,31}$

\subsubsection{In Vitro Antiplasmodial Assay}

Activity was determined against the 3D7 chloroquinesensitive strain of $P$. falciparum. Parasites were maintained in continuous culture using the method of Trager and Jensen ${ }^{33}$ with modifications. Growth medium consisted of RPMI 1640 containing $25 \mathrm{mM}$ HEPES, and further supplemented with $0.5 \%(\mathrm{w} / \mathrm{v})$ Albumax II, $22 \mathrm{mM}$ glucose, $0.65 \mathrm{mM}$ hypoxanthine, $0.05 \mathrm{mg} \mathrm{mL}^{-1}$ gentamicin and 2-4\% (v/v) human erythrocytes. Parasites were cultured at $37^{\circ} \mathrm{C}$ under an atmosphere of $5 \% \mathrm{CO}_{2}, 5 \% \mathrm{O}_{2}, 90 \%$ $\mathrm{N}_{2} \cdot{ }^{30,31}$ Compounds were prepared as $20 \mathrm{mM}$ stock solutions in dimethyl sulfoxide, sonicated for 10 minutes to enhance solubility and stored at $-20^{\circ} \mathrm{C}$ until use. To assess antimalarial activity, compounds were diluted to a final concentration of $20 \mu \mathrm{M}$ in culture medium, added to parasite cultures ( $2 \%$ parasitaemia, $1 \%$ haematocrit) in 96 well plates and incubated for $48 \mathrm{~h}$ at $37^{\circ} \mathrm{C}$ under an atmosphere of $5 \% \mathrm{CO}_{2}, 5 \% \mathrm{O}_{2}, 90 \% \mathrm{~N}_{2}$ Parasite viability was assessed using the parasite lactate dehydrogenase assay described by Makler et al..$^{34}$ Wells containing uninfected erythrocytes were used as negative controls ( $0 \%$ parasite viability) and untreated parasite-infected wells as positive controls (100\% parasite viability). To determine $\mathrm{IC}_{50}$-values, parasite cultures were incubated with 3-fold serial dilutions of test compounds and non-linear regression analysis carried out on dose-response plots of \% parasite viability vs. log[compound] using GraphPad Prism (v. 5.02) software.

\section{Acknowledgements}

We would like to acknowledge the National Research Foundation (NRF) for financial support. The Centre for Chemico- and Biomedicinal Research at Rhodes University is also acknowledged for testing our compounds for their antimalarial activity, using South African Medical Research Council (MRC) funds from National Treasury under its Economic Competitiveness and Support Package. We also gratefully acknowledge Dr Maritjie Stander of Central Analytical Facility (CAF) for mass spectrometry analysis. 


\section{${ }^{5}$ ORCID iDs}

T.E. Mtshare: (iD) orcid.org/0000-0003-0725-5738

S.D. Khanye: (D) orcid.org/0000-0003-0207-0718

\section{References}

1 WHO. World Malaria Report 2017, 2017.

2 WHO. In Global Report on Antimalarial Drug Efficacy and Drug Resistance, 2010, 17, 1-115.

3 U. Dalrymple, B. Mappin and P.W. Gething, Malaria mapping: understanding the global endemicity of falciparum and vivax malaria, BMC Med., 2015, 13, 140-147.

4 T.N.C. Wells, R.H. van Huijsduijnen and W.C. Van Voorhis, Malaria medicines: a glass half full?, Nat. Rev. Drug Discover., 2015, 14, 424-442.

5 J. Okombo and K. Chibale, Recent updates in the discovery and development of novel antimalarial drug candidates, MedChemComm. 2018, 9, 437-453.

6 C. Merritt, L.E. Silva, A.L. Tanner, K. Stuart and M.P. Pollastri, Kinases as druggable targets in trypanosomatid protozoan parasites, Chem. Rev., 2014, 114, 11280-11304.

7 M. Berninger, I. Schmidt, A. Ponte-Sucre and U. Holzgrabe, Novel lead compounds in pre-clinical development against African sleeping sickness, MedChem Commun., 2017, 8, 1872-1890.

8 WHO Media Centre: Trypanosomiasis, human African (sleeping sickness).

http://www.who.int/mediacentre/factsheets/fs259/en/ accessed 20 February 2018.

9 M. Njoroge, N.M. Njunguna, P. Mutai, D.S.B. Ongarora, P.W. Smith and K. Chibale, Recent approaches to chemical discovery and development against malaria and the neglected tropical diseases human African trypanosomiasis and schistosomiasis, Chem. Rev., 2014, 114, 11138-11163.

10 A.C. Lima Leite, J.W. Pontes Espíndola, M.V. de Oliveira Cardoso and G.B. de Oliveira Filho, Privileged structures in the design of potential drug candidates for neglected diseases, Curr. Med. Chem., 2018, 25, $1-30$.

11 O. Afzal, S. Kumar, M.R. Haider, M.R. Ali, R. Kumar, M. Jaggi and $\mathrm{S}$. Bawa, A review on atnicancer potential of bioactive heterocycle quinoline, Eur. J. Med. Chem., 2015, 97, 871-910.

12 S. Jain, V. Chandra, P.K. Jain, K. Pathak, D. Pathak and A. Vaidya Comprehensive review on current developments of quinoline-based anticancer agents, Arab. J. Chem., 2016, http://dx.doi.org/10.1016/j.arabjc.2016.10.009

13 M.C. Mandewale, U.C. Patil, S.V. Shedge, U.R. Dappadwad and R.S Yamgar, A review on quinnline hydrazone derivatives as a new classof potent antitubercular and anticancer agents, Beni-Suef Univ. J. Basic Appl. Sci., 2017, 6, 354-361.

14 R.S. Keri and S.A. Patil, Synthesis of hexahdrofuro[3,2-c]quinoline, a martinelline type analogues and invesigation of its biological activity, Biomed. Pharmacother., 2014, 68, 1161-1175.

15 S. Vandekerckhove and M. D'hooghe, Quinoline-based antimalarial hybrid compounds, Bioorg. Med. Chem., 2015, 23, 5098-5119.

16 I.V. Ukrainets, L. Yangyang, A.A. Tkach, O.V. Gorokhova and A.V. Turov, 4-Hydroxy-2-quinolones 165. 1-R-4-hydroxy-2-1,2-dihydroquinoline-3-carbaldehydes and their thiosemicarbazones. Synthesis, structure and biological properties, Chem. Heterocycl. Compd., 2009, 45, 705-714.

17 A. Srivastava and R.M. Singh, Vilsmeier-Haack reagent: a facile synthesis of 2-chloro-3-formylquinolines from $\mathrm{N}$-arylacetamides and transformation into different functionalities, Indian J. Chem., 2005, 44, 1868-1875.

18 O. Meth-Cohn, B. Narine and B. Tarnowski, A versatile new synthesis of quinoline and related fused pyridines, part 5 . The synthesis of 2-chloroquinoline-3-cabraldehydes, J. Chem. Soc., Perkin Trans. 1, 1981, $1,1520-1530$

19 B.-Q. Zou, X. Lu, Q.-P. Qin, Y.-X. Bai, Y. Zhang, M. Wang, Y.-C. Liu,
Z.-F. Chen and H. Liang, Three novel transition metal complexes of 6-methyl-2-oxo-quinoline-3-carbaldehyde thiosemicarbazone: synthesis, crystal structure, cytotoxicity and mechanism of action, RSC Adv., 2017, 7, 17923-17933.

20 N. Pribut, C.G.L. Veale, A.E. Basson, W.A.L. van Otterlo and S.C. Pelly, Application of the Huisegen cycloaddition and 'click' reaction toward various 1,2,3-triazoles as HIV non-nucleoside reverse transcriptase inhibitors, Bioorg. Med. Chem. Lett., 2016, 26, 3700-3704.

21 H.C. Kolb, M.G. Finn and K.B. Sharpless, Click chemistry: diverse chemical function from a few good reactions, Angew. Chem. Int. Ed., 2001, 40, 2004-2021.

22 C.W. Torn e, C. Christensen and M. Meldal, Peptidotriazoles on solid phase: $[1,2,3]$ triazoles by regiospecific copper(I)catalysed 1,3-dipolar cycloadditions of terminal alkynes to azides, J. Org. Chem., 2002, 67, 3057-3064.

23 V.V. Rostovtsev, L.G. Green, V.V. Fokin and K.B. Sharpless, A stepwise Huisgen cycloaddition process: copper(I)-catalyzed regioselective "ligation" of azides and terminal alkynes, Angew. Chem. Int. Edn. 2002, 41, 2596-2599.

24 X. Du, C. Guo, E. Hansell, P.S. Doyle, C.R. Caffrey, T.P. Holler, J.H. McKerrow and F.E. Cohen, Synthesis and structure-activity relationship study of potent trypanocidal thiosemicarbazone inhibitors of the trypanosomal cysteine protease cruzain, J. Med. Chem., 2002, 45, 2695-2707.

25 J. Song, L.M. Jones, G.D.K. Kumar, E.S. Conner, L. Bayeh, G.E Chavarria, A.K. Charlton-sevcik, S. Chen, D.J. Chaplin, M.L. Trawick and K.G. Pinney, Synthesis and biochemical evaluation of thiochromanone and thiosemicarbazone analogues as inhibitors of cathepsin L, ACS Med. Chem. Lett., 2012, 3, 450-453.

26 S.D. Khanye, G.S. Smith, C. Lategan, P.J. Smith, J. Gut, P.J. Rosenthal and K. Chibale, Synthesis and in vtro evaluation of gold(I) thiosemicarbazone complexes for antimalarial activity, J. Inorg. Biochem., 2010, 104, 1079-1083.

27 I. Chiyanzu, C. Clarkson, P.J. Smith, J. Lehman, J. Gut, P.J. Rosenthal and K. Chibale, Design, synthesis and anti-plasmodial evaluation in vitro of new 4-aminoquinoline isatin derivatives, Bioorg. Med. Chem., 2005, 13, 3249-3261.

28 D.S. Raja, G. Paramaguru, N.S.P. Bhuvanesh, J.H. Reibenspies, R. Renganathan and K. Natarajan, Effect of terminal $N$-substitution in 2-oxo-1,2-dihydroquinoline-3-carbaldehyde thiosemicarbazones on the mode of coordination, structure, interaction with protein, radical scavenging and cytotoxci activity of copper(II) complexes, Dalton Trans., 2011, 40, 4548-4559.

29 E. Ramachandran, D.S. Raja, N.S.P. Bhuvanesh and K. Natarajan Mixed ligand palladium(II) complexes of 6-methoxy-2-oxo-1,2dihydroquinoline-3-carbaldehyde $4 \mathrm{~N}$-substituted thiosemicarbazones with triphenylphosphine co-ligand: synthesis, crystal structure and biological properties, Dalton Trans., 2012, 41, 13308-13323.

30 O.O. Oderinlo, M. Tukulula, M. Isaacs, H.C. Hoppe, D. Taylor, V.J. Smith and S.D. Khanye, New thiazolidine-2,4-dione derivatives combined with organoemtallic ferrocene: synthesis, structure and antiparasitic activity, Appl. Organometal. Chem., 2018, e4385.

31 C.M. Adeyemi, Faridoon, M. Isaacs, D. Mnkandhla, H.C. Hoppe, R.W. Krause and P.T. Kaye, Synthesis and antimalarial activity of $\mathrm{N}$-benzylated (N-arylcarbamoyl)alkylphosphonic acid derivatives, Bioorg. Med. Chem., 2016, 24, 6131-6138.

$32 \mathrm{H}$. Hirumi and K. Hirumi, Continous cultivation of Trypanosoma brucei blood stream forms in a medium containing a low concentration of serum protein without feeder cell layers, J. Parasitol., 1989, 75, 985-989.

$33 \mathrm{~W}$. Trager and J.B. Jensen, Human malaria parasites in continuous culture, Science, 1976, 193, 673-675.

34 M.T. Makler, J.M. Ries, J.A. Williams, J.E. Bancroft, R.C. Piper, B.L. Gibbins and D.J. Hinrichs, Parasite lactate dehydrogenase as an assay for Plasmodium falciparum drug sensitivity, Am. J. Trop. Med. Hyg., $1993,48,739-741$ 